\title{
Centralidade e hierarquia do sistema financeiro brasileiro
}

Marco Crocco Cedeplar-FACE/UFMG

\section{Palauras-chave}

hierarquia urbana, sistema financeiro, centralidade.

Classificação JEL G2, O16, R51

Key words

urban hierarchy; financial system; centrality

JEL Classification G2, O16,

\section{Resumo}

O objetivo deste artigo é analisar a relação entre o sistema financeiro e o grau de centralidade do município onde esse está localizado. Para tanto, é realizada inicialmente uma discussão teórica, inédita, que visa analisar como o grau de centralidade pode afetar a forma de atuação de um banco em um local específico, tendo como ponto de partida a teoria da preferência de liquidez e a concepção de oferta de moeda endógena desenvolvida por Keynes. Após essa discussão teórica, será feita uma análise empírica sobre o caso brasileiro. Assim, é proposta uma hierarquia dos municípios brasileiros definida pela hierarquia do sistema financeiro neles existentes. Com base nessa hierarquia, a forma de atuação das agências bancárias em cada nível hierárquico é analisada. $\mathrm{O}$ estudo concluiu que o espaço é um importante elemento na definição das formas de atuação do sistema bancário, com consequências visíveis para o desenvolvimento econômico das regiốes.

\section{Abstract}

The purpose of this article is to analyze the relationship between the financial system and the degree of centrality of the city where it is located. Initially, a unique theoretical discussion is conducted to analyze how the degree of centrality can affect the behavior of a bank in a specific location, based on the theory of liquidity preference and the concept of endogenous currency supply derived by Keynes (1937). After this theoretical discussion, an empirical investigation is conducted of the Brazilian case. A hierarchy of Brazilian municipalities is proposed, based on the hierarchy of the financial system in them. Based on this bierarchy, the behavior of the banking system is analyzed at each hierarchical level. The study concludes that space is an important element in the definition of the ways banking system operates, with clear consequences for the economic development of the regions. 


\section{1_ Introdução}

É bastante conhecido na literatura sobre desenvolvimento urbano no Brasil o fato de a rede de cidades brasileiras ser caracterizada por uma grande fragmentação determinada pela existência de um pequeno número de grandes centros urbanos desenvolvidos e um grande número de pequenos núcleos urbanos pouco desenvolvidos (Lemos, 1988); Santos et al., 2002). Toda essa discussão é baseada no conceito de centralidade desenvolvido por Christaller (1966 [1933]) e Löasch (1954), para os quais a oferta de bens e serviços centrais determinaria o grau de centralidade de uma região. Exemplos desses bens e serviços seriam educação superior, sistema de saúde de grande complexidade, serviços bancários, entre outros.

O objetivo deste artigo é aprofundar essa discussão por meio da análise detalhada de um desses serviços centrais - sistema financeiro - e sua relação com o desenvolvimento econômico do município. Para tanto, é realizada inicialmente uma discussão teórica, inédita, acerca do funcionamento do sistema financeiro, com uma atenção especial ao sistema bancário e sua relação com o grau de centralidade de uma região. Busca-se aqui analisar como o grau de centralidade pode afetar a forma de atuação de um banco em um local específico. No entanto, para que tal relação possa ser analisada, se faz necessário entender a moeda, em todas as suas dimensóes, como capaz de afetar o lado real da economia, tanto no curto quanto no longo prazo. Para isso, assume-se neste trabalho a teoria da preferência de liquidez de Keynes e a concepção de oferta de moeda endógena desenvolvida por seus seguidores (Davidson, 1972; Dow; Hillard, 1995; Carvalho, 1992).

Após essa discussão teórica, uma análise empírica sobre o caso brasileiro é realizada. Por isso, é proposta uma hierarquia dos municípios brasileiros definida pela hierarquia do sistema financeiro neles existentes. Com base nessa hierarquia, a forma de atuação das agências bancárias em cada nível hierárquico é analisada. O estudo concluiu que o espaço é um importante elemento na definição das formas de atuação do sistema bancário, com consequências visíveis para o desenvolvimento econômico das regiōes.

\section{2_Moeda, espaço e centralidade}

\section{1_ Moeda e espaço: uma abordagem a partir da preferência pela liquidez}

Uma característica marcante na literatura acerca de economia regional é o 


\footnotetext{
Roberts e Fishkind (1979), Moore e Hill (1982) são autores de trabalhos iniciais que tentaram identificar fatores que poderiam levar ao racionamento de crédito em mercados regionais. Recentemente, autores da linha neokeynesiana como Faini et al. (1993) e Samolyk (1994) têm explorado o argumento da informaçáo assimétrica nos mercados de crédito regional.

2 Para um estudo empírico desta teoria em nível internacional, ver Dow (1990), Rodriguez-Fuentes (2006). Ver Amado (1997), Crocco et al. $(2005,2010)$ para a aplicação ao caso brasileiro.
}

pouco destaque dado à moeda e o seu papel para o desenvolvimento regional. Vários modelos de determinação da renda regional, como o neoclássico, o de causação cumulativa e o de insumo-produto, nâo consideram o impacto da moeda e de variáveis financeiras. Quando abordadas, tais variáveis são, em sua maioria, tratadas em modelos econométricos, nos quais algumas variáveis monetárias nacionais, consideradas exógenas, afetam a determinação regional da renda em função das características específicas de cada região. Assim, a moeda e os fluxos monetários têm sido considerados como resultado da diferença entre regióes e não como a causa dessa diferença. Neste contexto, a moeda é vista apenas como um véu que facilita as trocas e ajusta o nível geral de preços.

Os bancos, por sua vez, são também considerados neutros já que somente alocam poupanças disponíveis entre projetos alternativos. Regionalmente, o sistema bancário apenas afetará o desempenho das variáveis reais quando falhar na alocação do crédito nacional entre diferentes regiōes em virtude da presença de falhas de mercado, tais como informação imperfeita ou assimétrica, ou de barreiras à sua atuação, como custos de transação. ${ }^{1}$ Quando nenhum desses problemas ocorrerem, o mercado de crédito regional estará atuando de forma apropriada e equilibrará o fluxo financeiro inter-regional, fazendo com que as regióes não enfrentem problemas financeiros, uma vez que se deparam com uma curva de oferta de crédito perfeitamente elástica.

Embora as raízes de diferenças de renda regionais possam ser achadas em fatores estruturais, variáveis monetárias podem ser responsáveis pela manutenção e ampliação dessas diferenças de renda regional quando se adota uma abordagem em que a moeda e os bancos são sempre não neutros para o desenvolvimento regional. Trabalhos nessa linha de abordagem, de cunho pós-keynesiano, surgiram na última década na literatura econômica. ${ }^{2}$

A teoria monetária pós-keynesiana considera a moeda como parte integrante do processo econômico e, desta forma, uma clara distinção entre o lado monetário e o real da economia não pode ser feita (Dow, 1993). Para os póskeynesianos, a moeda não é exógena, entrando no sistema econômico através do crédito gerado pelos bancos e induzido pela sua demanda. Assim, o crédito permite determinar o investimento ao invés de de determinar o nível geral de preços, tornando a moeda parte integrante do processo econômico, e náo neutra. 
A abordagem acima descrita também se distingue das demais por tratar tanto o lado da oferta quanto o lado da demanda no mercado de crédito regional. Para esses autores, a oferta e a demanda de crédito são interdependentes e afetadas pela preferência pela liquidez, vinculada às expectativas que os agentes formam em um ambiente de incerteza. Do ponto de vista dos bancos, a preferência pela liquidez afetará negativamente a sua disposição em emprestar na região caso possuam expectativas pessimistas ou pouco confiáveis sobre essa. No lado da demanda por crédito, a preferência pela liquidez do público afetará suas respectivas definições de portfólio. Quanto maior a preferência pela liquidez, maiores as posiçôes em ativos líquidos desses agentes e menor sua demanda por crédito.

O que é fundamental para o presente trabalho é entender que a abordagem teórica aqui adotada abre a possibilidade de os bancos e/ou suas agências adotarem estratégias diferenciadas no território. Investigar tal possibilidade é o objetivo central deste artigo. Faremos isso analisando o caso brasileiro a seguir.

\section{3_ A Teoria do Lugar Central e a moeda}

Entre as diversas teorias de desenvolvimento urbano, talvez a que tenha tido o maior impacto na literatura, tanto de economia regional quanto de geografia econômica, foi a denominada Teoria do Lugar Central. ${ }^{3}$ Seus autores seminais foram Christaller (1966 [1933]) e Löasch (1954), embora vários outros tenham desenvolvido essa teoria. ${ }^{4}$

A "centralidade" de um lugar central seria derivada de sua capacidade em ofertar bens e serviços centrais. Em outras palavras, um lugar central desempenharia o papel de locus de oferta de serviços e bens centrais, tanto para si mesmo como para a sua vizinhança imediata ou área complementar. O que é importante salientar aqui é o fato de a definição de "lugar central" não ser apenas geográfica. Nas palavras de Christaller:

But in our sense, a place deserves the designation center only when it actually performs the function of a center. It performs this function if the inhabitants have professions which are bound by necessity to a central location. These professions will be called central professions. The goods being produced at the central place, just because it is central, and the services offered at the central place, will be called central

\footnotetext{
3 Para uma revisão acerca da literatura sobre desenvolvimento urbano, ver Goldstein e Moses (1973).

4 Nesta lista destacamse os trabalhos de Berry (1964), Berry e Pred (1961), Beckmann (1968), Parr 1997) e Bennett e Graham (1998), entre outros.
} 
goods and central services. Similarly, we shall speak of dispersed goods and dispersed services in reference to goods which are produced or offered at dispersed places and of indifferent goods and indifferent services in reference to goods which are not necessarily produced or offered centrally or dispersedly

(Christaller, 1966 [1933], p. 19).

Além disso, de acordo com Christaller, seria possível diferenciar entre bens centrais de maior ou menor ordem. Os bens centrais de maior ordem seriam produzidos e ofertados nos lugares centrais de maior ordem. Já os de bens centrais de ordem inferior seriam produzidos em lugares centrais de ordem inferior e ofertados tanto em lugares centrais de maior quanto de menor ordem. Exemplos de serviços centrais são: comércio, atividade bancária, administração pública, serviços culturais e religiosos, organizaçóes empresariais e profissionais, etc.

Fica evidente das definiçóes acima que o conceito de "lugar central" não é absoluto, mas sim relativo tanto à sua área complementar quanto aos demais lugares centrais. Christaller assim descreve:

Those places which have central functions that extend over a larger region, in which other central places of less importance exist, are called central places of a higher order. Those which have only local central importance for the immediate vicinity are called, correspondingly, central places of a lower and of the lowest order. Smaller places which usually have no central importance and which exercise fewer central functions are called auxiliary central places (Christaller, 1966 [1933], p. 17).

O segundo autor seminal em importância no desenvolvimento da Teoria do Lugar Central foi August Lösch (1954), em seu livro The economics of location, publicado em 1954. Um conceito fundamental para Lösch é de "área de mercado". Esta é derivada a partir da determinação da curva de demanda de um consumidor individual transportado para o espaço e considerando o custo de transporte (Ablas, 1982, p. 65). Com base nesse exercício, é possível determinar a área de mercado de um bem. Na definição final dessa área de mercado, existiriam elementos que trabalhariam no sentido de sua expansão, tais como especialização e produção em larga escala, e outros no sentido de sua dispersão, tal como custo de transporte. Como salientam Parr e Budd, a grande contribuição de Lösch (1954) foi mostrar que

with a dispersed pattern of demand, the spatial structure of supply was de- 
pendent on the interaction of economies of scale (discouraging the proliferation of supply points) and transport costs (encouraging their proliferation). The work of Christaller (1933), very much the co-founder of central place theory, was of a more inductive nature, and placed considerable emphasis on the hierarchical differentiation of places (Parr; Budd, 2000, p. 594).

Uma característica importante da discussão efetuada tanto por Christaller quanto por Lösch é a pequena relevância dada ao papel da moeda na construção de Teoria do Lugar Central. Em Christaller, a referência à moeda aparece em três momentos: primeiro, ao citar a atividade bancária como exemplo de serviços central (1966 [1933], p. 20); segundo, ao discutir as implicaçóes da densidade e da estrutura da população sobre o desenvolvimento de um lugar central (ele afirma que um lugar central com densidade populacional maior possibilitaria maior uso do capital necessário à produção de bens centrais) (p. 33), ${ }^{5}$ e, finalmente, ao admitir a possibilidade de custos de capital (taxas de juros) diferenciados no espaço.

Apesar de Christaller não expor sua concepção teórica sobre a moeda, as citações anteriores permitem inferir qual seja ela. A primeira referência é a mais simples uma vez que não possui nenhuma conotação teórica. Citar o sistema financeiro como um bem central implica apenas dizer que essa atividade econômica possui uma demanda dispersa e um padrão de oferta relacionado ao padrẫo de demanda.

Já as demais citações admitem inferências mais conclusivas. A segunda, relativa à possibilidade de um maior uso de capital em áreas densamente povoadas, expressa claramente a concepção clássica de fundos emprestáveis. Isso pode ser visto de duas formas. Em primeiro lugar, como mostrado anteriormente, uma regiáo mais densamente povoada permitiria maior consumo de bens centrais e, consequentemente, maior renda auferida. É justamente esta última que poderia fornecer a poupança necessária para maior uso de capital. Ou seja, o maior uso se relacionaria a uma maior poupança. Em segundo lugar, o maior uso também poderia ser resultado da existência de mais oportunidades de utilização, dada a diversidade produtiva decorrente. No entanto, esse maior uso só pode ser assegurado se o sistema bancário for passivo, no sentido de que é um mero intermediador entre poupadores e investidores. Ou seja, a função clássica de sistema bancário na teoria dos fundos emprestáveis.
5 And finally, the dense population enables a greater use of the capital necessary for the production of central goods (Christaller, 1966 [1933], p. 33). 
Por fim, a última citação é a que merece mais destaque por permitir interpretaçôes distintas do ponto de vista da teoria monetária.

Uma primeira observação que merece destaque está no fato de o diferencial de taxa de juros ser tratado apenas do ponto de vista dos custos de produção. Para Christaller, estes últimos são importantes na medida em que determinam o preço do bem central, e este pode interferir na renda auferida no lugar central. A renda de um lugar central, por sua vez, seria o fator mais importante na dinâmica desse lugar central. Assim sendo, discutir custos de produção significa discutir potencial de desenvolvimento do lugar central, bem como a definição do limite crítico da demanda necessária à produção do bem. Em outras palavras, podem interferir na área de mercado de um bem central e, desta forma, no tamanho e na distribuição de lugares centrais.

No entanto, a possibilidade de controvérsia ocorre quando se discutem as causas das variaçóes nos custos de capital. De acordo com Christaller,

Only in the interest rate is there any strong variation, due to the coverage of risk. On the local level, this element of uncertainty causes a higher cost, as can happen, for example, in border areas [...]. A high interest rate for capital means higher production costs and, therefore, higher prices for variables cost goods, or lesser profits for goods of fixed supply. Therefore, central places in such areas must sell their goods at higher prices, which, as a rule, lead to a migration of consumption to neighboring central places (with higher centrality) where prices are lower. Near unstabilized borders, the central places will have, therefore, small complementarity areas and will show limited development (Christaller, 1966 [1933], p. 95-96).

O ponto central aqui é determinar como a incerteza afeta a taxa de juros. Isso não fica claro na discussão feita por Christaller. Por um lado, seria possível interpretar tal incerteza exclusivamente do ponto de vista dos produtores. Ou seja, em regiōes de conflito, como é o caso de regióes de fronteira, o risco de inadimplência seria maior, o que levaria os bancos a elevarem as taxas de juros. Por outro lado, também seria possível interpretar essa incerteza do ponto de vista da teoria da preferência pela liquidez. Vale dizer, as decisóes relativas às formas alternativas de valorização e manutenção da riqueza por parte dos bancos levariam a uma menor disposição em emprestar em regióes com maior grau de incerteza, fato esse expresso por meio do diferencial da taxa de juros. Embo- 
ra possam parecer similares, essas duas interpretações possuem conteúdos teóricos claramente distintos e com implicaçôes diferentes do ponto de vista da teoria monetária. Como visto, admitir a teoria da preferência pela liquidez por parte dos bancos significa dar a esses papel ativo na gestáo de seu ativo e, consequentemente, na dinâmica de uma região. Isso é completamente distinto da mera incorporação do risco de inadimplência ao cálculo da taxa de juros. Neste caso, os bancos são passivos, sendo que os juros mais elevados é resultado de fatores estruturais da economia (lado real exclusivo) e não comportamentais dos bancos. ${ }^{6}$

Lösch (1954) aborda a questão da moeda de forma similar a Christaller, ou seja, através dos impactos sobre os custos de produção. Contudo o faz mais explicitamente, em uma seção inteira (18 páginas) do capítulo 26 de seu livro, mediante o estudo de diferenciais de taxa de juros. Naquela seção do livro, ele elenca estatísticas que mostram, para os Estados Unidos, que as taxas de juros tendem a ser mais altas quanto mais distantes as agências bancárias estiverem de um centro financeiro, notadamente Nova York, caindo à proporção que se aproximam de outro centro financeiro competidor.
Para explicar tais fatos estilizados, o autor se utiliza da teoria dos fundos emprestáveis e de falhas de mercado. Isso fica evidente já no momento em que ele formula a questão a ser respondida após a análise estatística: Por que a oferta e a demanda por capital é equilibrada somente a um alto preço? (Lösch, 1954, p. 468). A pergunta acima formulada tem como hipótese básica o fato de a taxa de juros ser o "preço" que equilibraria a oferta e a demanda por capital, hipótese essa central na teoria dos fundos emprestáveis.

As respostas fornecidas por Lösch a essa pergunta seriam duas:

i. a formação de capital (poupança) em regióes mais afastadas e menos desenvolvidas seria inferior à demanda aí existente. Os motivos que explicariam tal fato estariam relacionados aos fatores que afetam o processo de formação e alocação de poupança, tais como lucros menores devido às caracteríticas da estrutura produtiva (maior peso da agricultura); maior necessidade dos bancos em manterem reservas, o que implicaria menor volume de poupança disponível para empréstimos, entre outras;

\footnotetext{
6 Para uma discussão mais detalhada da comparação entre efeitos estruturais e comportamentais sobre a taxa de juros, ver RodriguezFuentes (2006).
} 
ii. existiria uma conexão imperfeita com mercados de capitais em regióes mais desenvolvidas, onde a situação seria inversa (demanda inferior à oferta). Em outras palavras, imperfeiçóes de mercado impediriam uma livre movimentação de capital entre regiôes mais desenvolvidas para menos desenvolvidas. Entre os fatores que impediriam essa livre movimentação, estariam: dificuldade de obter informação sobre os tomadores de empréstimos; excesso de intermediação - fato esse que elevaria o custo da movimentação e o "risco da distância”:

$\mathrm{He}$ [o emprestador da regiáo central] does not know men and conditions from his own experience and cannot keep in touch with further developments, which in pioneer regions particularly may be stormy and uncertain. Information and credit bureaus may compensate partly for this lack of personal knowledge, but they cannot make up for it enterely" (Lösch, 1954, p. 472).7

Essa forma de incorporar a moesão bastante similares ao conceito de distância operacional discutido por autores novos keynesianos (Alessandrini, 2007). desenvolvida. Entre os autores que assim o fizeram, vale destacar o tratamento dado por Dicken e Lloyd (1990). Para esses, moeda é tratada como capital, e assume-se que esse possa variar no espaço determinando, assim, variaçóes nos custos de produção. No entanto, deve ficar claro que, apesar desse avanço, o entendimento do significado da moeda ainda é restrito, com uma clara abordagem novo keynesiana baseada em imperfeiçôes de mercado. Tomem-se, como exemplo, as seguintes passagens:

The market for capital thus consists of a complex, interlocking network of financial institutions - banks, finance corporations, insurance companies, government agencies, and so on - that serves to accumulate savings and disburse investment capital to would be hires of the factor (Dicken; Lloyd, 1990, p. 162).

We can therefore look at the locational impact of capital in terms of the spatial disparity between supply and demand for the factor and its mobility in matching the two at different locations (Dicken; Lloyd, 1990, p. 162).

The accumulation of capital within an economic system depends on the level of savings, the willingness of savers to invest, and the level of net 
capital inflows from the outside. This represents broadly the supply side of the situation. On the demand side we must take into account the level of actual or expected profits in the system and the relationship to profit levels in other systems to which capital might flow (Dicken; Lloyd, 1990, p. 164).

Nas passagens acima descritas, fica evidente a confusão entre finance e funding, ${ }^{8}$ principalmente ao tratar bancos e outras instituiçóes do sistema financeiro de forma idêntica. Características históricas e setoriais de distintas regiōes determinariam diferenciais tanto de acumulação de poupanças quanto de demanda de investimentos, podendo tais funçôes não ser idênticas. Além disso, a mobilidade do capital seria, nesse contexto, mais afeita ao capital monetário, que teoricamente poderia ser considerado como plenamente móvel:

Within the same currency area, trading block, or nation, monetary capital is assumed to be highly, or even perfectly, mobile - free to move at no perceptible cost from place to place (Dicken; Lloyd, 1990, p. 165).

No entanto, os autores consideram que "descontinuidades" sociais, políticas e econômicas tendem a impedir essa livre movimentação:
The most significant of all these discontinuities is that between the advanced and underdeveloped nations. Even within homogeneous systems, however, the free flow of monetary capital cannot be said to be 'perfect' mobile either sectorally or spatially. In some sense it is - for large, well-known corporations, funds may be easy as the nearest telephone. But for the small firm or the nonstandard capital accumulation, there may be no effective mobility, spatially or otherwise, in the factor. Finally, governments these days exert a powerful impact on the flow of capital for development, regulating its overall levels by policy instrument and making it more readily available in some areas than others (Dicken; Lloyd, 1990, p. 167).

A conclusão lógica desse argumento é aceitar a hipótese de que o custo do capital, aqui expresso por meio das taxas de juros, seria diferenciado no território. De fato, os autores mostram vários trabalhos, principalmente do início do século XIX, que demonstram a ocorrência de taxas de juros diferenciadas nos EUA. Os autores até citam Lösch na discussão desse tema.

Finalmente, ainda comentando o trabalho de Lösch, os autores discutem as afirmativas de que fatores como distância e pouco conhecimento das instituições ajudariam a explicar a pouca
${ }^{8}$ Os termos finance e funding são utilizados neste artigo com base na concepção keynesiana. Neste contexto, finance seria o processo de criação de moeda pelos bancos necessário para atender à demanda por moeda antes de o investimento ser efetivamente realizado. Funding seria o processo de captação pelo sistema financeiro da poupança gerada pelo investimento efetuado com o finance. Para uma discussão mais detalhada, ver Davidson (1972) e Carvalho (1992). 
mobilidade de capital. Apesar de reconhecerem o desenvolvimento, tanto da regulação financeira quanto da tecnologia, esses afirmam que tais conclusões continuam válidas nos dias atuais. Para tanto, baseiam-se nos trabalhos de Estall (1972) e Gertler (1984):

[...] as both Estall (1972) and Gertler (1984) suggest, it is not necessarily cost per se that is important. Interest rate - the cost of capital - may not vary a great deal geographically within countries like United States, but the willingness of finance capital institutions to lend money for development is certain to vary, as anyone who has ever sought an overdraft or a bank loan will know (Dicken; Lloyd, 1990)

Citando Estall (1972), os autores concluem:

We conclude that capital funds are an important geographical variable in the internal location problem. Capital is nor equally available at all locations, given identical risks and opportunities; and the constraints that operate to impede its equal availability must, by extension, act also as constraints upon location (Estall, 1972, p. 197-198, p. 169).

Apesar de a visão de Lösch e de autores mais recentes deverem ser destacadas no sentido de terem se preocupa- do em incorporar a dimensão da moeda em sua discussão, não se pode negar que o referencial teórico utilizado para tanto não dá à moeda papel relevante, uma vez que são as variáveis reais que determinam tanto a escassez ou não de poupança (pequena lucratividade da agricultura, por exemplo) quanto a restrição à livre mobilidade de capital (assimetria de informação, exemplificando).

Uma discussão distinta, mas igualmente importante, é feita por Parr e Budd (2000). Nesse trabalho, os autores explicitamente procuram relacionar a Teoria do Lugar Central com a estrutura espacial do sistema financeiro, analisando o caso do Reino Unido. Dado que essa é uma abordagem que dialoga diretamente com o objeto deste artigo, faz-se necessária uma análise mais detalhada do argumento apresentado.

De acordo com os autores, para utilizar a Teoria do Lugar Central a fim de explicar a localização de serviços bancários seria essencial alterar algumas hipóteses desta, notadamente em relação ao tratamento dado para os insumos. Como se sabe, no modelo proposto por Lösch, todos os insumos são ubíquos no espaço. De acordo, porém, com os autores,

in the case of financial services, inputs costs in their broadest sense display a 
significant variation over space, and cannot be excluded from the analysis. Related to this is the fact that financialservice activities operate across an established urban system, in which costs may vary substantially, both within a hierarchical level and (more dramatically) among levels (Parr; Budd, 2000, p. 594).

A primeira observação em relação ao trabalho de Parr e Budd (2000) referese à caracterização de sistema financeiro. Em um longo parágrafo, eles dizem:

The financial system consists of a multitude of flows, organized around two types of end-user. The first type comprises primary or ultimate lenders, who are drawn from individuals (saving out of their income), industrial and commercial companies, governments, and financial firms acting on their own account ('proprietary trading'). The second type of end-user concerns ultimate borrowers, who invest in real or tangible assets that are used in the production of goods and services. Such end-users include firms which issue stock or bonds, governments which issue bonds and individuals who acquire mortgages to fund house purchases, for example. The financial system links the two types of end-user. It mediates the relationship between savings and investment (the savings-investment identity in national-income accounts). This relationship involves the difference between the change in assets and the change in the net acquisition of financial liabilities. When savings increase, the increase in financial assets is greater than the increase in financial liabilities. In terms of a country's national accounts, this results in a net financial surplus. Conversely, when savings decrease, the increase in financial liabilities is greater than the increase in financial assets, the result being a net financial deficit (p. 597).

Três observaçóes emergem tendo em vista a leitura da citação anterior. Em primeiro lugar, a concepção de sistema financeiro apresentada por Parr e Budd é centrada em interpretações neoclássicas e novo keynesianas. Em segundo lugar, e derivado da primeira observação, o sistema financeiro é visto meramente como um intermediador entre poupadores e investidores, ou seja, nos termos do referencial teórico aqui adotado, o sistema só faria a função de funding, sendo negligenciada a função de finance. Em terceiro lugar, e ligada à primeira, esta é uma concepção clássica de fundos emprestáveis, em que a poupança é prévia ao investimento. Vale salientar que a concepção teórica aqui adotada não des- 
conhece a identidade entre poupança e investimento nas contas nacionais. No entanto, a partir do momento em que é dado um sentido de causalidade a tal identidade, essa deixa de ser identidade e passa a ser uma teoria. Na citação, a teoria passa a existir quando os autores condicionam as ocorrências de superávit e déficit financeiro líquido às alterações no nível de poupança.

Uma característica dos mercados financeiros destacada pelos autores refere-se à existência de atores denominados market-makers. Esses seriam definidos pelo desempenho de quatro funçôes:

First, to act as auctioneers in organizing transactions, handling client orders and participating in trading; secondly, to act as price stabilizers, buying at low prices and selling at high prices, so that those prices oscillate around a mean, which establishes market effciency; thirdly, to act as information processors and contribute to the pricediscovery process, so that the price of a security approximates its true price; fourthly, to supply 'immediacy' - i.e. to match immediately a buy order with a sell order in order to avoid 'execution risk' or the delay in waiting for another end-user to agree to a transaction (Demsetz, 1968, p. 598).
Ao exercer tais funçōes, consideradas pelos autores como essenciais para o bom funcionamento do mercado de capitais, os market-makers procuram auferir lucros por meio da diferença de preços nas atividades de compra e venda de títulos e açôes. Os autores procuram mostrar que esse spread estaria condicionado a melhor ou pior possibilidade dos market-makers em exercerem as quatro funçóes listadas. Essa possibilidade, por sua vez, estaria condicionada pelas características do território onde se desempenhariam tais funções. Em mercados maiores, tanto a velocidade quanto o volume de informações são maiores em razão das economias de aglomeração existentes, fazendo com que o spread dos market-makers seja diminuído:

In other words, external economies of scale are realized because traders receiving a given price signal cannot insulate this from the market, owing to the scale and rapidly of transmission of price information. In this connection, it was noted by Demsetz (1968) that the spreads on individual stocks traded on the New York Stock Exchange were negatively related with trading volumes, suggesting that the concentration of dealing in individual stocks at a large exchange is based on 
the presence of external economies of scale (Parr; Budd, 2000, p. 604).

A discussão anterior deixa evidente que, para os autores, existe uma relação entre a atividade do sistema financeiro e a centralidade de uma região. Além do enfoque baseado no spread, os autores também exploram outra faceta da relação entre centralidade e sistema financeiro, quais sejam as economias de aglomeração.

Uma importante característica na discussão de "lugar central" relaciona-se à interdependência locacional entre firmas, que, na abordagem tradicional, é tratada por intermédio de atividades de varejo e na provisão de serviços. No caso específico dos serviços financeiros, é possível identificar a ocorrência tanto de economias de escala quanto de escopo externas à firma que permitiriam justificar o processo aglomerativo dessas atividades, fato esse que contribuiria para o fortalecimento da centralidade de determinados locais. Essa ocorrência seria determinada pelo fato de as atividades financeiras também apresentarem economias de localização, urbanização e de atividades complexas.

As economias de localização estariam presentes tanto mediante o aumento de receitas em virtude das economias de escala de screening dos potenciais clientes (uso compartilhado de cadastro, por exemplo) e especializaçóes produtivas quanto mediante as reduções de custo (como, por exemplo, por meio da existência de disponibilidade de mão de obra especializada, entre outros). Entre as economias urbanas, das quais o setor financeiro poderia usufruir, estariam

The availability of well-developed
transport and communication facili-
ties and municipal services [...] the
availability of specialized business
services not specific to a particular ac-
tivity, as well as the advantage of ur-
ban amenity (broadly defined) and the
derived or indirect advantage of a pool
of qualified labor (Parr; Budd, 2000, p. 603 ).

Como as economias de urbanização tendem a crescer com o aumento do tamanho da concentração urbana, pode-se inferir que firmas que forneçam serviços financeiros apresentam a propensão de se localizar em grandes cidades ou centros metropolitanos.

Finalmente, as economias de atividades complexas estariam presentes no setor financeiro principalmente por intermédio dos custos de transação, particularmente os relacionados à aquisição de informação. Isso ocorreria, por exemplo, em centros que possu- 
íssem, simultaneamente, no seu interior atividades de gestão de portfólios, derivativos e câmbio.

\section{4_Preferência pela liquidez, centralidade e hierarquia urbana e a construção do espaço}

Como visto, embora no desenvolvimento da Teoria do Lugar Central a discussão acerca da moeda venha crescentemente sendo incorporada, a teoria monetária adotada não permite maior entendimento dessa relação. Assim sendo, o que se pretende nesta seção é discutir as abordagens sobre desenvolvimento urbano sob a ótica da teoria de preferência pela liquidez de Keynes.

Partindo da Teoria do Lugar Central, uma centralidade elevada implica uma grande oferta de bens centrais, que, por sua vez, estimula a diversificação dos setores industriais e de serviços. Essa diversificação abre maiores possibilidades de investimentos por parte dos bancos, uma vez que eles podem variar seus portfólios, não somente entre ativos líquidos e ilíquidos, como também em relação a uma maior gama de ativos ilíquidos, com distintos graus de maturidade, diferentes setores, parcela de mercado, etc. Essa é uma diferença fundamental entre um lugar central e sua vizinhança.
Além disso, as economias de aglomeração derivadas de economias de escala, economias de localização e urbanização, associadas ao processo de diversificação dos setores industrial e de serviços, introduzem outro incentivo à redução da incerteza na região. Esse mecanismo foi salientado por Jacobs (1968) com o nome de sistema econômico de reciprocidade (economic reciprocating system), que nada mais é do que um processo de diversificação do sistema produtivo associado à introdução de outros produtos em distintos setores. Tal processo é possível devido ao desenvolvimento do setor de exportação e permite à cidade aumentar seu crescimento econômico, o que, por sua vez, possibilita o aumento da exportação de serviços e bens. Esse processo também atrairá firmas de diferentes setores para a cidade, aumentando as externalidades do local, o que torna a regiáo mais atrativa.

Do ponto de vista do sistema financeiro, não somente os seus custos serão reduzidos em razão das externalidades geradas pelas economias de aglomeração, como também aumentarão as oportunidades de investimento para os diversos setores industriais e de serviços. Desta forma, pode-se argumentar que, quanto maior a centralidade, menor a preferência pela liquidez dos bancos 
e maior a disposição desses em ofertar crédito para diferentes tipos de projeto. Em outras palavras, existiria maior disposiçáo dos bancos em ofertar o $f$ nance para o desenvolvimento dos projetos de investimento. Isso desencadearia um círculo virtuoso entre economias de aglomeração e oferta e demanda por crédito, reforçando o processo de concentração da oferta de crédito em lugares centrais. Além disso, o sistema financeiro procuraria aumentar o número de agências e provisão de serviços em lugares centrais tanto porque suas operaçôes estão sujeitas a economias de escala e escopo, e transbordamento (spillovers) de informaçóes, quanto pelo fato de seus principais custos (informação, coordenação e transação) serem sensíveis à escala de operação.

Essa relação da centralidade com o sistema bancário também se faz presente na gestão do passivo deste. Como mostra a literatura (Chick, 1992; Dow, 1999), uma característica atual do sistema bancário seria a capacidade desse em gerenciar seu passivo de forma mais ativa (liability management). Isso implicaria uma política ativa tanto de marketing como também, e fundamental para a discussão aqui realizada, de oferta de produtos variados, buscando aumentar a captação de recursos. Nas palavras de Dow,
The expansion of the banking system, facilitated by the enhanced confidence and the enlarged supply of reserves, in turn fuels a much greater expansion of non-banking financial intermediation with bank deposits as its base. At the fifth stage (which is characterized the British banking system in the 1970s), banks find themselves facing fierce competition for financial services from new non-bank's finance intermediaries. This competition has been the product of the bank's success. The banks are forced to become much more productive, seeking lending opportunities and the deposits to match them, that is, to engage in liability management (Dow, 1999, p. 38-39).

Nesse processo, o papel da centralidade de uma região, determinada pelo tamanho de sua população, da ren$\mathrm{da}$ e da diversidade de sua estrutura industrial e de serviços, é essencial para o desenvolvimento dessa atividade bancária. Tal diversidade determina a existência de uma gama de potenciais clientes para os bancos com distintas preferências pela liquidez, significando necessidades de formas diferenciadas para preservar e ou aumentar suas riquezas. Isso possibilitaria aos bancos a criação de inovaçôes financeiras diversas de forma a oferecer produtos padronizados para essas distintas necessidades. 
As implicaçôes desse processo são amplas. De um lado, isso possibilita aumento significativo das reservas bancárias. Embora na perspectiva aqui adotada a oferta de crédito não seja restrita pelo volume de reservas, este, por sua vez, é fundamental a todo o desenvolvimento do sistema financeiro. Segundo Dow,

although traditional banking is declining in relative importance within the financial system in terms of volume of traditional banking business [illiquid assets and liabilities-used-as-money], it nevertheless retains its pivotal importance in providing the money base on which the rest of the system is built. This is turn continues to allow banks to play their distinctive role in providing direct loans to borrowers as an alternative to borrowing in securities markets. [...] The different spatial characterization of potential borrowers means that bank finance be more important in some regions than others. Similarly, portfolio behavior on the asset side (particularly the desire for liquidity) may differ from one region to another (Dow, 1999, p. 40).

Por outro lado, isso permitiria a ampliação do funding. Como mostrado anteriormente, o processo de inves- timento, segundo a abordagem aqui utilizada, é iniciado através do finance, que é a obtenção de recursos financeiros de curto prazo nos bancos. Esse processo só é finalizado a partir do momento em que a poupança gerada por meio desse investimento é transformada em funding:

The process of transformation of shortterm into long-term liabilities is called funding. To be feasible, a funding operation requires the existence of wealth holders desiring permanent abodes of wealth, in contrast of banks which, when creating finance, are only searching for short-lived commitments (Carvalho, 1992, p. 151).

É possível argumentar que, em regiōes com pequena centralidade, somente o finance ocorre integralmente, e o processo de funding é apenas parcialmente internalizado, criando dificuldades ainda maiores para os investidores ali localizados. Isso ocorreria pelo motivo de a liquidez dos ativos das regióes serem menores, fazendo com que a poupança gerada pelo processo de investimento seja transferida para regióes mais centrais. Ademais, deve ser destacado o fato de que o grau de desenvolvimento do sistema financeiro é determinante para o sucesso da transformação do finance em funding: 
The more sophisticated and diversified the financial system is, in terms of types of financial instruments and duration of commitments, the more efficient it will be to intermediate resources between savers and investors" (Carvalho, 1992, p. 152).

Este processo se torna mais importante nos dias atuais tendo em vista que os bancos passaram a utilizar massivamente o processo de securitizaçáo. Esse seria o sexto estágio bancário proposto por Chick (1992) e Dow (1999). De acordo com Dow,

[...] to attempt to sell off assets in order to reduce their capital requirements and to increase banks' appeal in equity markets. At the same time, the banks sought to avoid a recurrence of this situation of being caught with illiquid assets of dubious value. The outcome was the development of securitization (Gardener, 1988). Banks turned existing loans into marketable securities and developed the provision of financial services in securities markets, facilitating borrowing by means of issuing securities, rather than lending directly themselves. At the same time, they encouraged the development of markets of derivative products which offered banks profit-making opportunities off the balance sheet, and thus not subject to capital requirements (although the requirements have since been changed

to try to capture exposure to off-balance sheet risk) (Dow, 1999, p. 38-39).

Desta forma, é possível argumentar que firmas localizadas em regióes mais centrais possuem melhores alternativas para buscar funding, inclusive no mercado de securities, em vez de buscar esses recursos diretamente nos bancos. Já firmas pequenas e médias, localizadas em regiôes de vizinhança à central ou com centralidades menores, teriam apenas a possibilidade de recorrer ao sistema bancário para a obtenção dos recursos necessários para o seu investimento. Ou seja, o impacto da centralidade na configuração do sistema bancário determinaria vantagens competitivas, em termos de acesso ao financiamento, para as firmas ali localizadas. ${ }^{9}$

Nesse ponto, os dois lados do processo de investimento se juntam. Pode ser argumentado que náo somente a preferência pela liquidez dos bancos é afetada pela centralidade, mas também a do público de forma geral. Isso, por sua vez, levaria a uma maior demanda por crédito. Ou seja, dado que a centralidade implicaria maiores economias externas e de escala, pode-se afirmar que o ambiente econômico em regióes centrais seria menos incerto e, portanto, levaria as firmas a terem mais disposição
9 Uma comprovação empírica da relação entre centralidade e funding pode ser encontrada em Wójick (2009). Este artigo mostra que firmas localizadas em centros financeiros têm mais probabilidades de se financiarem via emissão de açóes no mercado de capital do que firmas localizadas na periferia. 
em investir. Assim, quanto maior a centralidade, maior também a demanda por crédito. Além disso, como visto acima, essa maior disposição a se endividar encontraria formas mais variadas de ocorrer em regiôes centrais, podendo ser desse o tradicional endividamento junto aos bancos, quanto a emissão de debêntures, açóes, entre outras.

Além da demanda por crédito, a preferência pela liquidez também afeta a disposição do púbico em geral em manter seus ativos em forma mais ou menos líquida. Isso implica escolher entre manter seus recursos na forma de depósitos à vista (mais líquido) ou outras formas de aplicações financeiras, tais como depósitos a prazo (mais ilíquidos). Desta forma, se o grau de centralidade influencia o grau de incerteza de uma região, e consequentemente a preferência pela liquidez, é possível argumentar que, quanto maior a centralidade, menor a preferência pela liquidez do público, menor a propensão a reter ativos mais líquidos e, portanto, maiores as possibilidades do sistema bancário em ter um passivo mais ilíquido, no sentido de maiores prazos de maturação.

A centralidade de um região é importante para determinar a decisão dos bancos quanto à localização de suas agências e headquarters. Como salienta- do por Martin (1999), no caso de bancos de varejo, a decisão sobre onde localizar uma nova agência é positivamente influenciada pelo nível de renda e pelo tamanho da população de uma regiâo. Como a centralidade ajuda a concentrar pessoas e aumenta a renda de uma regiáo, pode-se alegar que, quanto maior a centralidade, maior será a possibilidade de o banco decidir instalar uma agência nessa região.

No entanto, como salientado, o sistema financeiro não é passivo em relação ao desenvolvimento da região. A preferência pela liquidez dos bancos pode facilitar o desenvolvimento de uma região, na medida em que ela permite ao banco se tornar mais propenso a ofertar crédito naquele local. Pela mesma razão, porém, esse processo contém fortes elementos que reforçam as disparidades regionais.

De um lado, é possível inferir que, quanto maior a centralidade de uma região, maior será a preferência pela liquidez de sua vizinhança (relativamente ao lugar central), uma vez que esta última não possui os serviços ofertados pelo centro e, desta forma, tornar-se-á menos atrativa tanto para a indústria quanto para os bancos. Isso tornará mais difícil para a vizinhança diversificar seus setores industriais e de serviços, reforçando aqui sua posição de hierarquia inferior. 
Por outro lado, as condições periféricas deverão se reproduzir, já que essas estáo vinculadas à centralidade do centro. A lógica de reprodução do sistema nessa regiáo é condicionada e reforçada pela lógica do sistema de produção do centro. A questão não é ser desenvolvido ou subdesenvolvido em termos de dois estágios distintos e sequenciais. $\mathrm{O}$ que se discute é a lógica de reprodução (e acumulação) do capital no espaço. Desta forma, lugares centrais não são distribuídos igualmente pelo espaço devido ao fato de que o processo de acumulação e reprodução do capital no setor terciário implica a existência de hierarquia entre centros urbanos.

Assim, o resultado da livre movimentação das forças de mercado resulta em um desenvolvimento regional desigual. Neste sentido, pode-se deduzir que desenvolvimento regional também significa distribuição de centralidades ou a construção de muitas centralidades através do espaço. O que é aqui sugerido é que o sistema financeiro desempenha papel crítico nesse processo.

Por fim, caberia discutir como a moeda se relaciona com o processo de construção de centralidades em espaços periféricos. Como visto anteriormente, existem três fatores que tornam o território mais desigual em regiōes periféri- cas, a saber: i) a pequena densidade urbana determinada pela pior distribuição espacial dessa renda; ii) o entorno do núcleo urbano geralmente de subsistência, significando que o núcleo urbano não é capaz de desaglomerar atividades econômicas complementares para seu entorno; e, iii) a porosidade da demanda local, que resulta em uma área de mercado regional geograficamente extensa, mas com baixa intensidade da demanda por unidade de distância.

Todas essas caracteríscas determinam a construção de um espaço fortemente fragmentado em regióes atrasadas, com uma estrutura urbana fortemente hierarquizada. É possível, portanto, argumentar que, quanto mais hierarquizada for uma estrutura urbana, maior será o diferencial de preferência pela liquidez entre as regióes. Ou seja, em regióes periféricas, o diferencial de preferência pela liquidez entre regiōes é significativamente maior graças à fragmentação do espaço, fazendo com que tal diferencial se torne cada vez maior. Além disso, a distribuição espacial do sistema financeiro também se torna extremamente fragmentada, não só com grandes diferenciais entre regióes na concessão de crédito, como também na oferta de serviços bancários. Nas palavras de Dow, 
As financial systems develop, the nonbank financial intermediaries expand relative to the banks; [...] Together, the banks and the non-banks financial intermediaries provide financial services to non-financial bussines. The nature, terms and availability of these services are the fundamental economic signifcance. To the extent that these services and their availability differ from one locality to another, the economic development of these localities is bound to be affected. These differences can arise from the local character of financial institutions, and from the degree to which local bussiness is dependent on such local financial institutions (Chick; Dow, 1988; Dow, 1999, p. 43-44).

\section{5_Hierarquia urbana e sistema financeiro no Brasil}

Feita a análise tendo em vista o corte regional, passa-se agora para a investigação da relação entre o sistema bancário e a construção de centralidades no Brasil. O objetivo é fornecer alguns elementos que permitam a construção de uma ponte entre estudos sobre o comportamento da moeda na perspectiva póskeynesiana e uma temática-chave, tanto para economistas regionais quanto para geógrafos: a centralidade urbana.
Como amplamente discutido na literatura, o sistema financeiro, de forma geral, sempre foi considerado um bem central e, portanto, um elemento fundamental na construção de uma hierarquia urbana. No entanto, o sistema financeiro não é necessariamente homogêneo no espaço, significando que as suas características internas vão determinar a capacidade de influenciar a construção de centralidades e, consequentemente, de hierarquias urbanas distintas, principalmente em países periféricos como o Brasil. Assim sendo, procura-se, nesta seção, hierarquizar os municípios brasileiros de acordo com as características do sistema financeiro ali instalado.

A metodologia adotada para estabelecer a hierarquia baseou-se na diversidade de tipos de instituição financeira existentes em cada município brasileiro. Assume-se que instituições financeiras amplamente distribuídas no território realizam funçóes menos centrais. Por outro lado, instituições pouco difundidas realizam funçóes mais centrais. Assim, a hierarquia da instituição financeira será definida pela sua distribuiçãao espacial.

A fonte de dados básica para determinar a hierarquia acima sugerida foi a RAIS para o ano de 2007. Essa base fornece, entre outras coisas, o número de estabelecimentos em cada município para 
setores definidos de acordo com a classificação CNAE. Desta forma, foram considerados 36 tipos de instituição financeira (listadas no Quadro 1 do Anexo).

Com base nessa definição de tipos de instituiçáo financeira, foram coletados os dados relativos à quantidade de cada tipo de estabelecimentos em cada município brasileiro. Procedeu-se, então, à verificação da dispersão no território brasileiro de cada uma das atividades listadas acima. Ou seja, observou-se em quantos municípios (de uma amostra de 3.837) cada tipo de atividade está presente. Como dito, a hipótese aqui adotada é que as atividades centrais são menos difundidas no território. Os resultados estão mostrados na Tabela 1 .

Como pode ser visto, a instituição financeira "Fundos de investimento" era a mais central no Brasil, em 2007, estando presente em apenas 5 dos 3.837 municípios da amostra. Na outra ponta, estão os "Bancos múltiplos, com carteira comercial e bancos comerciais", presentes em 90\% dos municípios da amostra. Para cada tipo de atividade, um peso, definido arbitrariamente, foi atribuído. Tais pesos relacionam-se de forma inversa com o grau de centralidade do tipo de instituição financeira. Assim sendo, para as atividades mais centrais ("Fundo de investimento", por exemplo), foi atribuí- do o peso 5. Do outro lado da escala, para as atividades menos centrais, o peso atribuído foi 1 .

Para hierarquizar os municípios, procedeu-se à multiplicação da quantidade de cada tipo de instituição localizada em um município específico pelo seu respectivo peso. O resultado final por município foi obtido por meio da soma dos valores obtidos para cada tipo de instituição financeira ali existente. Com isso, estabeleceu-se uma hierarquia de municípios brasileiros a partir do peso de cada tipo de instituição financeira no seu interior.

A partir dessa hierarquização, os municípios brasileiros que possuíam agências bancárias em 2008 foram classificados em quatro grupos. ${ }^{10} \mathrm{Os}$ resultados obtidos estão mostrados na Tabela 2.

A primeira observação derivada da análise da Tabela 2 é a extrema desproporção, em termos de escopo e escala, na distribuição dos tipos de instituição financeira entre os municípios brasileiros. O cluster 1 possui no seu interior cerca de 99\% dos municípios da amostra (3.800), com um valor ponderado médio de cerca de 79 . O cluster 2, por sua vez, é formado por 31 cidades, representando cerca de $0,81 \%$ dos municípios, com um valor ponderado médio de
$10 \mathrm{O}$ método de agrupamento utilizado foi o não hierárquico. Neste caso, o número de clusters é definido anteriormente, e o programa define em qual cluster cada município é alocado. A alternativa a esse método é o agrupamento hierárquico, no qual o próprio programa define o número de clusters final. No entanto, tal procedimento foi descartado devido ao fato de o presente exercício utilizar um número elevado de indivíduos (3.837 municípios) e de variáveis (36 tipos de atividade financeira). 
Tabela 1_Hierarquia de tipos de instituição financeira

(continua)

\begin{tabular}{|c|c|c|c|c|c|}
\hline Quartil & $\begin{array}{l}\text { Nível } \\
\text { Hierárquico }\end{array}$ & Atividades Econômicas & Frequência & $\begin{array}{l}\text { Proporção do Total } \\
\text { de Municípios }\end{array}$ & $\begin{array}{l}\text { Pesos } \\
\text { Atribuidos }\end{array}$ \\
\hline \multirow{9}{*}{10} & 1 & Fundos de investimento & 5 & $0,13 \%$ & 5 \\
\hline & 2 & Bancos múltiplos, sem carteira comercial & 8 & $0,21 \%$ & 5 \\
\hline & 3 & Bancos de desenvolvimento & 10 & $0,26 \%$ & 5 \\
\hline & 4 & Securitização de crédito & 10 & $0,26 \%$ & 5 \\
\hline & 5 & Holdings de instituições financeiras & 11 & $0,29 \%$ & 5 \\
\hline & 6 & Bancos de investimento & 12 & $0,31 \%$ & 5 \\
\hline & 7 & Arrendamento mercantil & 14 & $0,37 \%$ & 4 \\
\hline & 8 & Sociedade de crédito ao microempreendedor & 15 & $0,39 \%$ & 4 \\
\hline & 9 & Resseguros & 17 & $0,44 \%$ & 4 \\
\hline \multirow{9}{*}{20} & 10 & Crédito imobiliário & 19 & $0,50 \%$ & 4 \\
\hline & 11 & Sociedades de capitalização & 19 & $0,50 \%$ & 4 \\
\hline & 12 & $\begin{array}{l}\text { Administração de bolsas e } \\
\text { mercados de balcáo organizados }\end{array}$ & 22 & $0,57 \%$ & 4 \\
\hline & 13 & Agências de fomento & 35 & $0,91 \%$ & 4 \\
\hline & 14 & $\begin{array}{l}\text { Atividades de administração } \\
\text { de fundos por contrato ou comissão }\end{array}$ & 49 & $1,28 \%$ & 4 \\
\hline & 15 & Seguros-saúde & 51 & $1,33 \%$ & 3 \\
\hline & 16 & Outras sociedades de participação, exceto holding & 56 & $1,46 \%$ & 3 \\
\hline & 17 & Previdência complementar fechada & 64 & $1,67 \%$ & 3 \\
\hline & 18 & Previdência complementar aberta & 69 & $1,80 \%$ & 3 \\
\hline
\end{tabular}


(conclusão)

\begin{tabular}{|c|c|c|c|c|c|}
\hline Quartil & $\begin{array}{l}\text { Nível } \\
\text { Hierárquico }\end{array}$ & Atividades Econômicas & Frequência & $\begin{array}{l}\text { Proporção do Total } \\
\text { de Municípios }\end{array}$ & $\begin{array}{l}\text { Pesos } \\
\text { Atribuidos }\end{array}$ \\
\hline \multirow{8}{*}{30} & 19 & Avaliação de riscos e perdas & 77 & $2,01 \%$ & 3 \\
\hline & 20 & $\begin{array}{l}\text { Sociedades de crédito, financiamento e investimento } \\
\text { - financeiras }\end{array}$ & 84 & $2,19 \%$ & 3 \\
\hline & 21 & $\begin{array}{l}\text { Atividades de intermediários em transaçôes } \\
\text { de títulos, valores mobiliários e mercadorias }\end{array}$ & 106 & $2,76 \%$ & 3 \\
\hline & 22 & $\begin{array}{l}\text { Administração de consórcio } \\
\text { para aquisição de bens e direitos }\end{array}$ & 147 & $3,83 \%$ & 3 \\
\hline & 23 & Seguros de vida & 151 & $3,94 \%$ & 3 \\
\hline & 24 & Adminstração de cartóes de crédito & 154 & $4,02 \%$ & 3 \\
\hline & 25 & Seguros não-vida & 205 & $5,35 \%$ & 3 \\
\hline & 26 & Holdings de instituiçóes não-financeiras & 221 & $5,76 \%$ & 3 \\
\hline \multirow{9}{*}{40} & 27 & $\begin{array}{l}\text { Atividades auxiliares dos seguros, previdência complemen- } \\
\text { tar e dos planos de saúde não especificadas anteriormente }\end{array}$ & 264 & $6,88 \%$ & 3 \\
\hline & 28 & Sociedades de fomento mercantil - factoring & 410 & $10,69 \%$ & 2 \\
\hline & 29 & Planos de saúde & 442 & $11,53 \%$ & 2 \\
\hline & 30 & $\begin{array}{c}\text { Atividades auxiliares dos serviços financeiros } \\
\text { não especificados anteriormente }\end{array}$ & 479 & $12,49 \%$ & 2 \\
\hline & 31 & $\begin{array}{l}\text { Outras atividades de serviços financeiros } \\
\text { não especificadas anteriormente }\end{array}$ & 564 & $14,71 \%$ & 2 \\
\hline & 32 & $\begin{array}{l}\text { Corretores e agentes de seguros, de planos } \\
\text { de previdência complementar e de saúde }\end{array}$ & 742 & $19,35 \%$ & 2 \\
\hline & 33 & Caixas econômicas & 1081 & $28,19 \%$ & 2 \\
\hline & 34 & Crédito cooperativo & 1188 & $30,96 \%$ & 2 \\
\hline & 35 & $\begin{array}{c}\text { Bancos múltiplos, com carteira comercial } \\
\text { e bancos comerciais }\end{array}$ & 3481 & $90,77 \%$ & 1 \\
\hline
\end{tabular}


7.886, ou seja, valor médio quase mil vezes superior ao observado no cluster anterior. Já o cluster 2 é composto de apenas cinco municípios, porém com um valor ponderado médio de 56.684,8 (cerca de sete vezes maior que o cluster 2). Por fim, o cluster 4 é composto de um único município (São Paulo) e com um valor ponderado de 260.774 (quase cinco vezes o valor do cluster 3 ).

As Tabelas 3 e 4, por seu turno, ajudam a entender melhor os fatores que caracterizam cada cluster. A Tabela 4 mostra o peso de cada atividade em cada cluster específico. Como pode ser observado, o cluster 1 apresenta forte concentração do peso das atividades financeiras em apenas dois tipos de instituição: "Bancos comerciais" e "Caixa econômica”. Esses dois tipos de instituição respondem por $55 \%$ do total do valor ponderado da hierarquia. O total de $80 \%$ do peso ponderado acumulado é obtido com sete tipos de instituição.

Tabela 2_Agrupamentos dos municípios brasileiros segundo tipo de instituição financeira

\begin{tabular}{|c|c|c|c|c|}
\hline & Agrupamento & Município & $\begin{array}{l}\text { Participação Relativa } \\
\text { no Total de Munícipios }\end{array}$ & Valor Ponderado \\
\hline \multirow{2}{*}{$\begin{array}{l}\square \\
\frac{5}{0} \\
\frac{0}{0} \\
\frac{0}{2}\end{array}$} & & São Paulo & & 260.774 \\
\hline & $\begin{array}{l}\text { Número Total de Municípios } \\
\text { e Valor Ponderado Médio }\end{array}$ & 1 & 0,03 & 260.774 \\
\hline \multirow{6}{*}{ 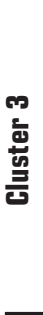 } & & Rio de Janeiro & & 118.929 \\
\hline & & Brasília & & 49.640 \\
\hline & & Porto Alegre & & 39.866 \\
\hline & & Belo Horizonte & & 39.602 \\
\hline & & Curitiba & & 35.387 \\
\hline & $\begin{array}{l}\text { Número Total de Municípios } \\
\text { e Valor Ponderado Médio }\end{array}$ & 5 & 0,13 & 56.685 \\
\hline \multirow{5}{*}{$\begin{array}{l}\mathbf{v} \\
\frac{5}{0} \\
\frac{0}{2} \\
\text { 름 }\end{array}$} & & Salvador & & 18.630 \\
\hline & & Recife & & 16.709 \\
\hline & & Fortaleza & & 15.627 \\
\hline & & Belém & & 14.185 \\
\hline & & Campinas & & \\
\hline
\end{tabular}


(conclusão)

\begin{tabular}{|c|c|c|c|c|}
\hline & Agrupamento & Município & $\begin{array}{l}\text { Participação Relativa } \\
\text { no Total de Munícipios }\end{array}$ & Valor Ponderado \\
\hline \multirow[t]{2}{*}{$\begin{array}{l}\mathbf{v} \\
\text { 험 } \\
\frac{0}{2} \\
\frac{0}{0}\end{array}$} & & $\begin{array}{c}\text { Goiânia } \\
\text { Osasco } \\
\text { Vitória } \\
\text { Barueri } \\
\text { Florianópolis } \\
\text { Ribeirão Preto } \\
\text { São Jose do Rio Preto } \\
\text { Manaus } \\
\text { Campo Grande } \\
\text { Cuiabá } \\
\text { Natal } \\
\text { Teresina } \\
\text { São Bernardo do Campo } \\
\text { João Pessoa } \\
\text { Londrina } \\
\text { Santos } \\
\text { Guarulhos } \\
\text { Saao Jose dos Campos } \\
\text { Bauru } \\
\text { Aracaju } \\
\text { Santo André } \\
\text { Maceió } \\
\text { São Luis } \\
\text { Sberlândia } \\
\text { Socaba } \\
\text { Sitén }\end{array}$ & & $\begin{array}{l}12.651 \\
11.903 \\
10.993 \\
10.659 \\
10.590 \\
7.830 \\
7.513 \\
6.159 \\
6.115 \\
5.777 \\
5.457 \\
5.433 \\
5.061 \\
5.060 \\
4.921 \\
4.903 \\
4.860 \\
4.849 \\
4.819 \\
4.635 \\
4.578 \\
4.566 \\
4.540 \\
4.485 \\
4.088 \\
3.971\end{array}$ \\
\hline & $\begin{array}{l}\text { Número Total de Municípios } \\
\text { e Valor Ponderado Médio }\end{array}$ & 31 & 0,81 & 7.886 \\
\hline \multirow{2}{*}{ 동 } & Número Total de Municípios & $\begin{array}{c}\text { Demais municípios } \\
\text { brasileiros }(3.800)\end{array}$ & & \\
\hline & e Valor Ponderado Médio & 3.800 & 99,04 & 79 \\
\hline
\end{tabular}

Fonte: Elaboraçấo própria, 2010. 
Tabela 3_ Distribuição dos tipos de instituição financeira por cluster

(continua)

\begin{tabular}{|c|c|c|c|c|c|c|c|c|}
\hline & \multicolumn{2}{|c|}{ Cluster 1} & \multicolumn{2}{|c|}{ Cluster 2} & \multicolumn{2}{|c|}{ Cluster 3} & \multicolumn{2}{|c|}{ Cluster 4} \\
\hline & $\begin{array}{c}\text { Total } \\
\text { Ponderado }\end{array}$ & $\begin{array}{l}\text { \% no total } \\
\text { do Cluster }\end{array}$ & $\begin{array}{c}\text { Total } \\
\text { ponderado }\end{array}$ & $\begin{array}{l}\text { \% no total } \\
\text { do Cluster }\end{array}$ & $\begin{array}{c}\text { Total } \\
\text { ponderado }\end{array}$ & $\begin{array}{l}\text { \% no total } \\
\text { do Cluster }\end{array}$ & $\begin{array}{c}\text { Total } \\
\text { ponderado }\end{array}$ & $\begin{array}{l}\text { \% no total } \\
\text { do Cluster }\end{array}$ \\
\hline $\begin{array}{l}\text { Bancos Comerciais + } \\
\text { bancos múltiplos com } \\
\text { carteira comercial }\end{array}$ & $113.381,00$ & 37,84 & $70.211,00$ & 28,72 & $76.749,00$ & 27,08 & $85.941,00$ & 32,96 \\
\hline Caixas econômicas & $51.834,00$ & 17,30 & $43.230,00$ & 17,68 & $39.568,00$ & 13,96 & $14.562,00$ & 5,58 \\
\hline Crédito cooperativo & $28.506,00$ & 9,51 & $4.964,00$ & 2,03 & $4.018,00$ & 1,42 & $1.170,00$ & 0,45 \\
\hline Planos de saúde & $26.004,00$ & 8,68 & $24.508,00$ & 10,02 & $16.778,00$ & 5,92 & $13.548,00$ & 5,20 \\
\hline $\begin{array}{l}\text { Atividades auxiliares dos } \\
\text { serviços financeiros náo } \\
\text { especificadas anteriormente }\end{array}$ & $13.826,00$ & 4,61 & $15.962,00$ & 6,53 & $13.702,00$ & 4,83 & $7.862,00$ & 3,01 \\
\hline $\begin{array}{l}\text { Corretores e agentes de } \\
\text { seguros, de planos de } \\
\text { previdência complementar } \\
\text { e de saúde }\end{array}$ & $12.646,00$ & 4,22 & $9.278,00$ & 3,80 & $8.132,00$ & 2,87 & $10.720,00$ & 4,11 \\
\hline $\begin{array}{l}\text { Outras atividades de } \\
\text { serviços financeiros não } \\
\text { especificadas anteriormente }\end{array}$ & $10.144,00$ & 3,39 & $6.428,00$ & 2,63 & $4.882,00$ & 1,72 & $2.828,00$ & 1,08 \\
\hline $\begin{array}{l}\text { Holdings de instituições } \\
\text { não financeiras }\end{array}$ & $9.165,00$ & 3,06 & $7.434,00$ & 3,04 & $12.771,00$ & 4,51 & $12.927,00$ & 4,96 \\
\hline $\begin{array}{l}\text { Administração de } \\
\text { consórcios para aquisição } \\
\text { de bens e direitos }\end{array}$ & $6.261,00$ & 2,09 & $8.991,00$ & 3,68 & $3.255,00$ & 1,15 & $3.729,00$ & 1,43 \\
\hline Seguros não vida & $4.887,00$ & 1,63 & $9.531,00$ & 3,90 & $19.149,00$ & 6,76 & $30.024,00$ & 11,51 \\
\hline $\begin{array}{l}\text { Administração de } \\
\text { cartóes de crédito }\end{array}$ & $4.425,00$ & 1,48 & $5.133,00$ & 2,10 & $2.139,00$ & 0,75 & $5.442,00$ & 2,09 \\
\hline
\end{tabular}


(continua)

\begin{tabular}{|c|c|c|c|c|c|c|c|c|}
\hline & \multicolumn{2}{|c|}{ Cluster 1} & \multicolumn{2}{|c|}{ Cluster 2} & \multicolumn{2}{|c|}{ Cluster 3} & \multicolumn{2}{|c|}{ Cluster 4} \\
\hline & $\begin{array}{c}\text { Total } \\
\text { Ponderado }\end{array}$ & $\begin{array}{l}\% \text { no total } \\
\text { do Cluster }\end{array}$ & $\begin{array}{c}\text { Total } \\
\text { Ponderado }\end{array}$ & $\begin{array}{l}\text { \% no total } \\
\text { do Cluster }\end{array}$ & $\begin{array}{c}\text { Total } \\
\text { Ponderado }\end{array}$ & $\begin{array}{l}\% \text { no total } \\
\text { do Cluster }\end{array}$ & $\begin{array}{c}\text { Total } \\
\text { Ponderado }\end{array}$ & $\begin{array}{l}\text { \% no total } \\
\text { do Cluster }\end{array}$ \\
\hline $\begin{array}{l}\text { Atividades auxiliares dos } \\
\text { seguros, da previdência } \\
\text { complementar e dos planos } \\
\text { de saúde não especificadas } \\
\text { anteriormente }\end{array}$ & $4.362,00$ & 1,46 & $2.898,00$ & 1,19 & $5.802,00$ & 2,05 & $4.569,00$ & 1,75 \\
\hline $\begin{array}{l}\text { Sociedades de fomento } \\
\text { mercantil - factoring }\end{array}$ & $4.042,00$ & 1,35 & $4.144,00$ & 1,70 & $2.308,00$ & 0,81 & $2.526,00$ & 0,97 \\
\hline $\begin{array}{l}\text { Sociedades de crédito, } \\
\text { financiamento e } \\
\text { investimento - financeiras }\end{array}$ & $2.628,00$ & 0,88 & $5.601,00$ & 2,29 & $2.889,00$ & 1,02 & $5.295,00$ & 2,03 \\
\hline Seguros de vida & $1.443,00$ & 0,48 & $2.082,00$ & 0,85 & $6.639,00$ & 2,34 & $6.429,00$ & 2,47 \\
\hline Avaliação de riscos e perdas & 987,00 & 0,33 & $1.278,00$ & 0,52 & 423,00 & 0,15 & 864,00 & 0,33 \\
\hline $\begin{array}{l}\text { Atividades de intermediários } \\
\text { em transações de títulos, } \\
\text { valores mobiliários e } \\
\text { mercadorias }\end{array}$ & 711,00 & 0,24 & $1.407,00$ & 0,58 & $8.001,00$ & 2,82 & $14.928,00$ & 5,72 \\
\hline $\begin{array}{l}\text { Previdência } \\
\text { complementar fechada }\end{array}$ & 693,00 & 0,23 & $3.813,00$ & 1,56 & $13.236,00$ & 4,67 & $2.586,00$ & 0,99 \\
\hline $\begin{array}{l}\text { Previdência } \\
\text { complementar aberta }\end{array}$ & 684,00 & 0,23 & $3.651,00$ & 1,49 & $6.873,00$ & 2,42 & $3.564,00$ & 1,37 \\
\hline Agências de fomento & 556,00 & 0,19 & $1.184,00$ & 0,48 & $1.288,00$ & 0,45 & 104,00 & 0,04 \\
\hline $\begin{array}{l}\text { Atividades de } \\
\text { administração de fundos } \\
\text { por contrato ou comissão }\end{array}$ & 556,00 & 0,19 & 312,00 & 0,13 & $1.884,00$ & 0,66 & $2.636,00$ & 1,01 \\
\hline Fundos de investimento & 340,00 & 0,11 & 0,00 & 0,00 & 0,00 & 0,00 & 0,00 & 0,00 \\
\hline $\begin{array}{l}\text { Outras sociedades } \\
\text { de participaçáo, } \\
\text { exceto holdings }\end{array}$ & 306,00 & 0,10 & 162,00 & 0,07 & 621,00 & 0,22 & $1.350,00$ & 0,52 \\
\hline Seguros saúde & 240,00 & 0,08 & $1.101,00$ & 0,45 & $6.129,00$ & 2,16 & $6.684,00$ & 2,56 \\
\hline
\end{tabular}


(conclusão)

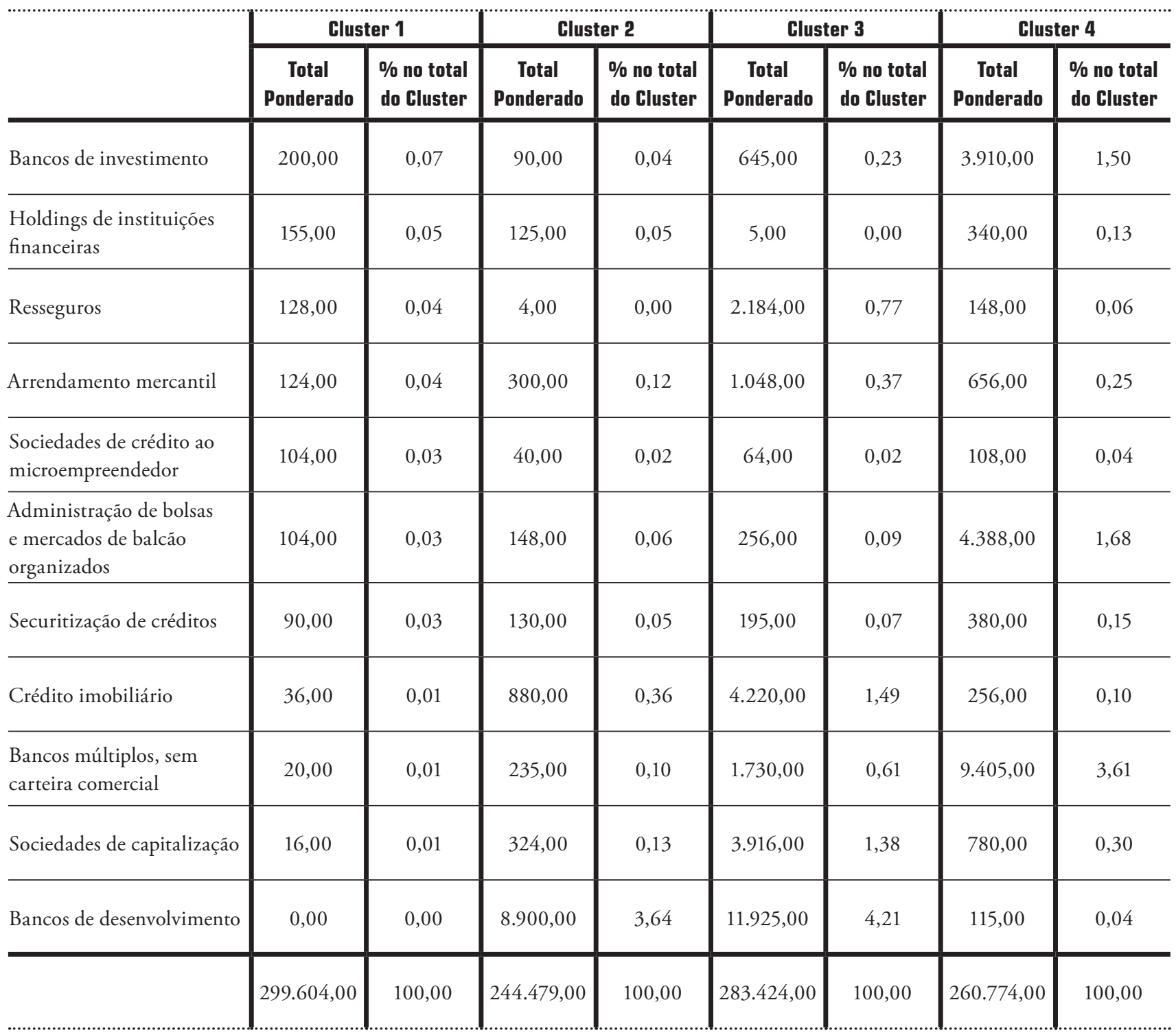

Fonte: Elaboraçáo própria, 2010. 
A Tabela 4 ajuda a visualizar o escopo da atuação dos tipos de instituição financeira por cluster. Como é visto, 91\% dos municípios do cluster 1 possuem pelo menos uma agência de banco comercial no seu interior. Essa é, sem dúvida alguma, a grande característica desse cluster. Depois desse tipo de atividade, a que se destaca são as instituições de crédito cooperativo, presentes em 30\% dos municípios do cluster (1.151). Em seguida, têm-se as "Caixas Econômicas", com presença em $27 \%$.

Quando os resultados das Tabelas 3 e 4 são comparados com os da Tabela 1, observa-se claramente que esse cluster só possui, tanto em escala quanto em escopo, oferta de instituições financeiras hierarquicamente inferiores. Além disso, como mostra a Tabela 1 do Anexo, entre os 15 tipos de atividade mais importantes desse cluster, sete estão no último quartil em termos de hierarquia (Tabela 1) e todos os 15 tipos nos dois últimos quartis inferiores. Esse cluster será, portanto, denominado de Sistema Financeiro Básico.

O cluster 2, por sua vez, tem suas duas atividades de maior peso ("Bancos comerciais" e "Caixas Econômicas") representando cerca de 56\% do total do valor ponderado médio do cluster. No entanto, ele apresenta maior diversifica- ção, quer seja de escala, quer seja de escopo. A marca de $80 \%$ do valor ponderado médio é obtida com o somatório das nove atividades mais importantes, mais do que o dobro observado para o cluster 1. Ademais, 12 tipos de instituição estão presentes em todos os municípios do cluster e 22 tipos estão presentes em mais de 50\% dos municípios. A Tabela 5 também mostra que, entre os 15 tipos de atividade mais importantes, seis estão no último quartil e 12 nos dois últimos quartis, como mostrado na Tabela 1. Esse cluster será denominado Sistema Financeiro Diversificado.

O cluster 3, composto de cinco cidades apenas (todas elas capitais de estados) apresenta uma composição de tipos de centro financeiro quase que completa, deixando de ter, no seu interior, apenas dois tipos de instituição financeira. As duas instituiçôes financeiras mais importantes representam $41 \%$ do valor ponderado total do cluster. A marca de $80 \%$ do valor ponderado total do cluster é alcançada com o somatório dos 12 principais tipos de instituição.

Além disso, dos 35 tipos de instituição listada, 25 estão presentes em todos os cinco municípios, sete estão presentes em mais de 50\% dos municípios, e duas em menos que 50\% (além das duas atividades completamente ausentes). 


\begin{tabular}{|c|c|c|c|c|c|c|c|c|}
\hline & \multicolumn{2}{|c|}{ Cluster 1} & \multicolumn{2}{|c|}{ Cluster 2} & \multicolumn{2}{|c|}{ Cluster 3} & \multicolumn{2}{|c|}{ Cluster 4} \\
\hline & $\begin{array}{l}\text { Número de } \\
\text { municípios }\end{array}$ & $\%$ & $\begin{array}{l}\text { Número de } \\
\text { municípios }\end{array}$ & $\%$ & $\begin{array}{l}\text { Número de } \\
\text { municípios }\end{array}$ & $\%$ & $\begin{array}{l}\text { Número de } \\
\text { municípios }\end{array}$ & $\%$ \\
\hline $\begin{array}{l}\text { Bancos Comerciais + bancos múltiplos } \\
\text { com Carteira Comercial }\end{array}$ & 3.444 & 91 & 31 & 100 & 5 & 100 & 1 & 100 \\
\hline Crédito cooperativo & 1.151 & 30 & 31 & 100 & 5 & 100 & 1 & 100 \\
\hline Caixas econômicas & 1.044 & 27 & 31 & 100 & 5 & 100 & 1 & 100 \\
\hline $\begin{array}{l}\text { Corretores e agentes de seguro, de planos } \\
\text { de previdência complementar e de saúde }\end{array}$ & 705 & 19 & 31 & 100 & 5 & 100 & 1 & 100 \\
\hline $\begin{array}{l}\text { Outras atividades de serviços financeiros } \\
\text { náo especificadas anteriormente }\end{array}$ & 527 & 14 & 31 & 100 & 5 & 100 & 1 & 100 \\
\hline $\begin{array}{l}\text { Atividades auxiliares dos serviços financeiros } \\
\text { náo especificadas anteriormente }\end{array}$ & 442 & 12 & 31 & 100 & 5 & 100 & 1 & 100 \\
\hline Planos de saúde & 405 & 11 & 31 & 100 & 5 & 100 & 1 & 100 \\
\hline Sociedade de fomento mercantil-factoring & 373 & 10 & 31 & 100 & 5 & 100 & 1 & 100 \\
\hline $\begin{array}{l}\text { Atividades auxiliares de seguro, da } \\
\text { previdência complementar e dos planos de } \\
\text { saúde não especificados anteriormente }\end{array}$ & 227 & 6 & 31 & 100 & 5 & 100 & 1 & 100 \\
\hline Holdings de instituições não-financeiras & 187 & 5 & 28 & 90 & 5 & 100 & 1 & 100 \\
\hline Seguros não vida & 168 & 4 & 31 & 100 & 5 & 100 & 1 & 100 \\
\hline Administração de cartão de crédito & 117 & 3 & 31 & 100 & 5 & 100 & 1 & 100 \\
\hline Seguro de vida & 116 & 3 & 29 & 94 & 5 & 100 & 1 & 100 \\
\hline $\begin{array}{l}\text { Administração de consórcios para } \\
\text { aquisição de bens e direitos }\end{array}$ & 110 & 3 & 31 & 100 & 5 & 100 & 1 & 100 \\
\hline $\begin{array}{l}\text { Atividades de intermediários em transção de } \\
\text { títulos, valores mobiliários e mercadorias }\end{array}$ & 75 & 2 & 25 & 81 & 5 & 100 & 1 & 100 \\
\hline $\begin{array}{l}\text { Sociedade de crédito, financiamento e } \\
\text { investimento- financeiras }\end{array}$ & 52 & 1 & 26 & 84 & 5 & 100 & 1 & 100 \\
\hline Avaliação de risco e perdas & 50 & 1 & 21 & 68 & 5 & 100 & 1 & 100 \\
\hline
\end{tabular}


(conclusão)

\begin{tabular}{|c|c|c|c|c|c|c|c|c|}
\hline & Cluste & & Cluste & & Cluste & & Cluste & \\
\hline & $\begin{array}{l}\text { Número de } \\
\text { municípios }\end{array}$ & $\%$ & $\begin{array}{l}\text { Número de } \\
\text { municípios }\end{array}$ & $\%$ & $\begin{array}{l}\text { Número de } \\
\text { municípios }\end{array}$ & $\%$ & $\begin{array}{l}\text { Número de } \\
\text { municípios }\end{array}$ & $\%$ \\
\hline Previdência complementar fechada & 34 & 1 & 24 & 77 & 5 & 100 & 1 & 100 \\
\hline $\begin{array}{l}\text { Outras sociedades de participação, } \\
\text { exceto holdings }\end{array}$ & 31 & 1 & 19 & 61 & 5 & 100 & 1 & 100 \\
\hline $\begin{array}{l}\text { Atividades de administração de } \\
\text { fundos por contrato ou comissão }\end{array}$ & 31 & 1 & 13 & 42 & 4 & 80 & 1 & 100 \\
\hline Agências de fomento & 22 & 1 & 7 & 23 & 5 & 100 & 1 & 100 \\
\hline Seguros saúde & 21 & 1 & 24 & 77 & 5 & 100 & 1 & 100 \\
\hline Resseguros & 12 & 0 & 1 & 3 & 3 & 60 & 1 & 100 \\
\hline $\begin{array}{l}\text { Administração de bolsas e mercados } \\
\text { de balcão organizados }\end{array}$ & 9 & 0 & 7 & 23 & 5 & 100 & 1 & 100 \\
\hline Arrendamento mercantil & 7 & 0 & 4 & 13 & 2 & 40 & 1 & 100 \\
\hline Sociedades de crédito ao microempreendedor & 7 & 0 & 4 & 13 & 3 & 60 & 1 & 100 \\
\hline Holdings de instituiçóes financeiras & 6 & 0 & 3 & 10 & 1 & 20 & 1 & 100 \\
\hline Fundos de investimento & 5 & 0 & 0 & 0 & 0 & 0 & 0 & 0 \\
\hline Bancos de investimentos & 4 & 0 & 2 & 6 & 5 & 100 & 1 & 100 \\
\hline Securitização de créditos & 4 & 0 & 2 & 6 & 3 & 60 & 1 & 100 \\
\hline Crédito imobiliário & 2 & 0 & 12 & 39 & 4 & 80 & 1 & 100 \\
\hline Bancos múltiplos, sem carteira comercial & 2 & 0 & 2 & 6 & 3 & 60 & 1 & 100 \\
\hline Sociedades de capitalização & 1 & 0 & 12 & 39 & 5 & 100 & 1 & 100 \\
\hline Bancos de desenvolvimento & 0 & 0 & 5 & 16 & 4 & 80 & 1 & 100 \\
\hline $\begin{array}{l}\text { Bancos de câmbio e outras instituições } \\
\text { de intermediação não-monetária }\end{array}$ & 0 & 0 & 0 & 0 & 0 & 0 & 0 & 0 \\
\hline
\end{tabular}

Fonte: Elaboração própria 2010 
Dos 15 tipos de atividade mais importantes (Tabela 1 do Anexo), cinco estão no último quartil, cinco no terceiro quartil, quatro no segundo quartil e uma no primeiro (Tabela 1). Dada essa composição, esse cluster será denominado Centro Financeiro de Segunda Ordem.

O último cluster analisado é o localizado no ponto mais alto da hierarquia. Composto apenas do município de São Paulo, ele não possui somente um tipo de atividade no seu interior. As duas instituiçóes financeiras mais importantes representam $44 \%$ do valor ponderado total do cluster. A marca de $80 \%$ do valor ponderado total do cluster é alcançada com o somatório dos 12 tipos de instituição de maior peso.

Vale salientar que, apesar de esse cluster apresentar diversificação de tipos de atividade no seu interior muito similar à observada no cluster Centro Financeiro de Segunda Ordem, a sua escala é muito superior à observada no cluster 4 . De fato, o valor ponderado médio de cada tipo de instituição desse cluster é superior aos valores observados nos demais tipos.

Entre os 15 tipos de atividade mais importantes (Tabela 1 do Anexo), quatro estão no último quartil, seis no terceiro quartil, dois no segundo quartil e duas no primeiro (Tabela 1). Dada essa composição, esse cluster será denominado Centro Financeiro de Primeira Ordem.

Um ponto mais geral a ser destacado surge da observação da Tabela 4: o tipo de instituiçãa com maior peso em todos os clusters é justamente o de menor nível hierárquico, ou seja, "Bancos comerciais e múltiplos". Isso pode ser explicado pelas características do sistema bancário no Brasil, caracterizado pela dominância de grandes bancos nacionais, com agências espalhadas pelas regióes. Ou seja, é basicamente pela agência bancária que o brasileiro tem acesso ao sistema financeiro como um todo. Ademais, é na agência bancária que os serviços básicos de um banco são ofertados e demandados, tais como abertura de conta-corrente, pagamento de dívidas, etc. Esses dois aspectos fazem das agências bancárias de bancos comerciais e múltiplos, espalhados pelo território, o tipo de instituição financeira menos central e presente em todos os clusters.

As Tabelas 5 e 6, por sua vez, ajudam a entender a distribuição das atividades pelos clusters. Todas as atividades classificadas como mais centrais e, consequentemente, localizadas no primeiro quartil da hierarquização feita anteriormente (Tabela 1) possuem sua maior participação relativa no cluster Centro Financeiro de Primeira Ordem, reforçando 
Tabela 5_Distribuição de tipos de atividade por cluster

(continua)

\begin{tabular}{|c|c|c|c|c|c|c|c|c|c|}
\hline 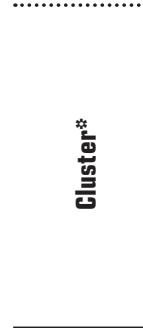 & 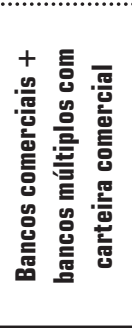 & 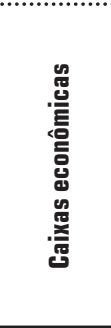 & 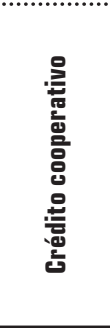 & 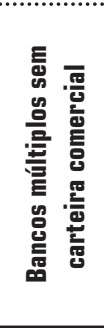 & 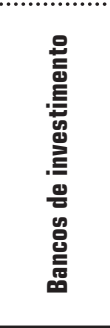 & 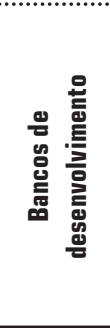 & 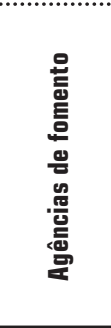 & 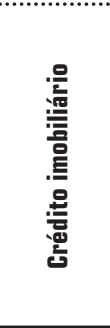 & 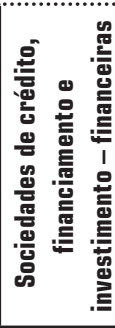 \\
\hline SFB & 32,74 & 34,74 & 73,74 & 0,18 & 4,13 & 0,00 & 17,75 & 0,67 & 16,01 \\
\hline SFD & 20,28 & 28,98 & 12,84 & 2,06 & 1,86 & 42,50 & 37,80 & 16,32 & 34,13 \\
\hline $\mathrm{CF} 2^{\circ}$ & 22,16 & 26,52 & 10,39 & 15,19 & 13,31 & 56,95 & 41,12 & 78,26 & 17,60 \\
\hline $\mathrm{CF} 1^{\circ}$ & 24,82 & 9,76 & 3,03 & 82,57 & 80,70 & 0,55 & 3,32 & 4,75 & 32,26 \\
\hline TOTAL & 100,00 & 100,00 & 100,00 & 100,00 & 100,00 & 100,00 & 100,00 & 100,00 & 100,00 \\
\hline
\end{tabular}

\begin{tabular}{|c|c|c|c|c|c|c|c|c|c|}
\hline 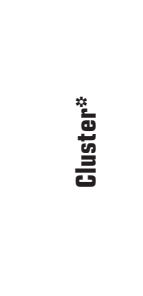 & 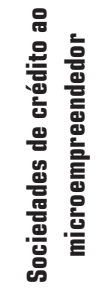 & 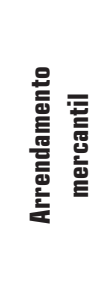 & 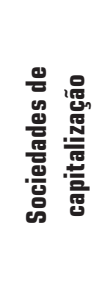 & 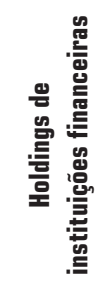 & 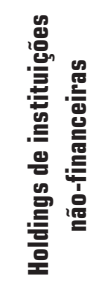 & 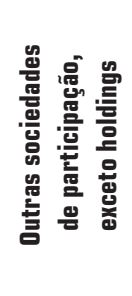 & 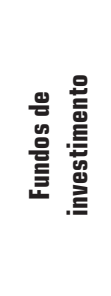 & 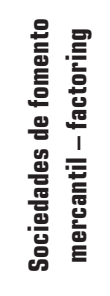 & 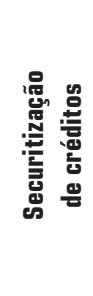 \\
\hline SFB & 32,91 & 5,83 & 0,32 & 24,80 & 21,67 & 12,55 & 100,00 & 31,04 & 11,32 \\
\hline SFD & 12,66 & 14,10 & 6,43 & 20,00 & 17,58 & 6,64 & 0,00 & 31,83 & 16,35 \\
\hline $\mathrm{CF} 2^{\circ}$ & 20,25 & 49,25 & 77,76 & 0,80 & 30,19 & 25,46 & 0,00 & 17,73 & 24,53 \\
\hline CF $1^{\circ}$ & 34,18 & 30,83 & 15,49 & 54,40 & 30,56 & 55,35 & 0,00 & 19,40 & 47,80 \\
\hline TOTAL & 100,00 & 100,00 & 100,00 & 100,00 & 100,00 & 100,00 & 100,00 & 100,00 & 100,00 \\
\hline
\end{tabular}




\begin{tabular}{|c|c|c|c|c|c|c|c|c|c|}
\hline 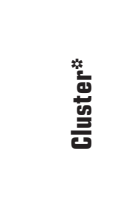 & 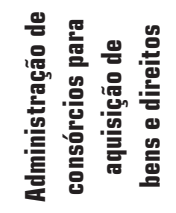 & 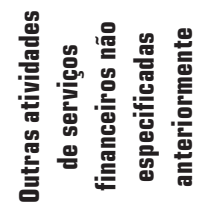 & 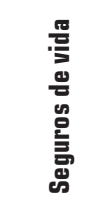 & 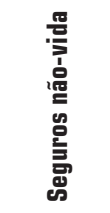 & 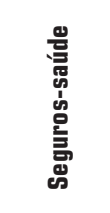 & 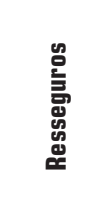 & 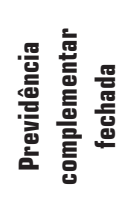 & 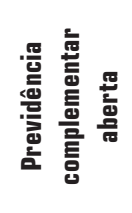 & 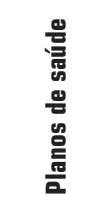 \\
\hline SFB & 28,16 & 41,78 & 8,70 & 7,69 & 1,70 & 5,19 & 3,41 & 4,63 & 32,17 \\
\hline SFD & 40,43 & 26,47 & 12,55 & 14,99 & 7,78 & 0,16 & 18,76 & 24,72 & 30,32 \\
\hline $\mathrm{CF} 2^{\circ}$ & 14,64 & 20,11 & 40,01 & 30,11 & 43,30 & 88,64 & 65,11 & 46,53 & 20,76 \\
\hline CF $1^{\circ}$ & 16,77 & 11,65 & 38,75 & 47,21 & 47,22 & 6,01 & 12,72 & 24,13 & 16,76 \\
\hline TOTAL & 100,00 & 100,00 & 100,00 & 100,00 & 100,00 & 100,00 & 100,00 & 100,00 & 100,00 \\
\hline
\end{tabular}

\begin{tabular}{|c|c|c|c|c|c|c|c|c|}
\hline 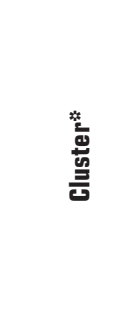 & 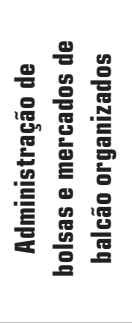 & 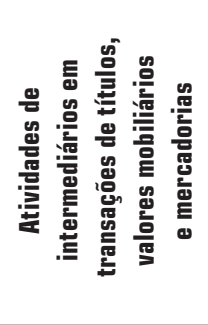 & 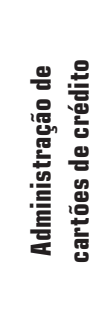 & 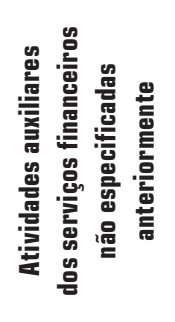 & 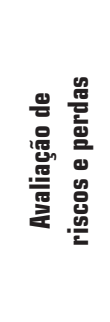 & 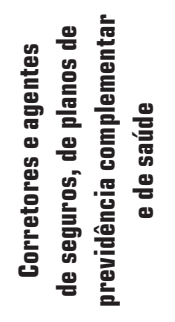 & 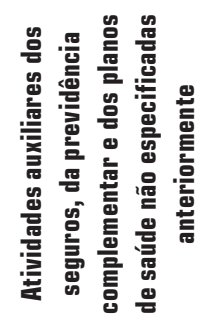 & 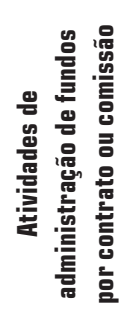 \\
\hline SFB & 2,12 & 2,84 & 25,82 & 26,92 & 27,79 & 31,01 & 24,74 & 10,32 \\
\hline SFD & 3,02 & 5,62 & 29,95 & 31,08 & 35,98 & 22,75 & 16,44 & 5,79 \\
\hline $\mathrm{CF} 2^{\circ}$ & 5,23 & 31,94 & 12,48 & 26,68 & 11,91 & 19,94 & 32,91 & 34,97 \\
\hline $\mathrm{CF} 1^{\circ}$ & 89,62 & 59,60 & 31,75 & 15,31 & 24,32 & 26,29 & 25,91 & 48,92 \\
\hline TOTAL & 100,00 & 100,00 & 100,00 & 100,00 & 100,00 & 100,00 & 100,00 & 100,00 \\
\hline
\end{tabular}

Fonte: Elaboração Própria, 2010.

SFB $=$ Sistema Financeiro Básico,

SFDv $=$ Sistema Financeiro Diversificado.

$\mathrm{CF} 2^{\circ}=$ Centro Financeiro de Segunda Ordem.

$\mathrm{CF} 1^{\circ}=$ Centro Financeiro de Primeira Ordem . 
Tabela 6_Atividades financeiras cujo cluster possui maior participação relativa

\begin{tabular}{|c|c|c|c|}
\hline $\begin{array}{l}\text { Centro Financeiro } \\
\text { de Primeira Ordem }\end{array}$ & $\begin{array}{l}\text { Centro Financeiro } \\
\text { de Segunda Ordem }\end{array}$ & $\begin{array}{c}\text { Sistema Financeiro } \\
\text { Diversificado }\end{array}$ & Sistema Financeiro Básico \\
\hline $\begin{array}{l}\text { Bancos múltiplos } \\
\text { sem carteira comercial }\end{array}$ & Bancos de desenvolvimento & $\begin{array}{l}\text { Sociedades de crédito, } \\
\text { financiamento e investimento } \\
\text { - financeiras }\end{array}$ & $\begin{array}{l}\text { Bancos Comerciais + } \\
\text { Bancos Múltiplos } \\
\text { com carteira comercial }\end{array}$ \\
\hline Bancos de investimento & Agências de fomento & $\begin{array}{l}\text { Sociedades de fomento } \\
\text { mercantil - factoring }\end{array}$ & Caixas econômicas \\
\hline $\begin{array}{l}\text { Sociedades de crédito ao } \\
\text { microempreendedor }\end{array}$ & Crédito imobiliário & $\begin{array}{l}\text { Administração de consórcios } \\
\text { para aquisição de bens e direitos }\end{array}$ & Crédito cooperativo \\
\hline $\begin{array}{c}\text { Holdings de instituiçóes } \\
\text { não-financeiras }\end{array}$ & Arrendamento mercantil & Avaliação de riscos e perdas & Fundos de investimento \\
\hline $\begin{array}{l}\text { Outras sociedades de } \\
\text { participaçáo, exceto holdings }\end{array}$ & Sociedades de capitalização & & Planos de saúde \\
\hline Securitização de créditos & Seguros de vida & & $\begin{array}{l}\text { Corretores e agentes de seguros, } \\
\text { de planos de previdência } \\
\text { complementar e de saúde }\end{array}$ \\
\hline Seguros náo vida & Resseguros & & \\
\hline Holdings de instituiçōes financeiras & $\begin{array}{l}\text { Atividades auxiliares dos seguros, } \\
\text { da previdência complementar e dos } \\
\text { planos de saúde não especificadas }\end{array}$ & & \\
\hline $\begin{array}{l}\text { Administração de bolsas e } \\
\text { mercados de balcão organizados }\end{array}$ & $\begin{array}{c}\text { Previdência } \\
\text { complementar fechada }\end{array}$ & & \\
\hline $\begin{array}{l}\text { Atividades de intermediários } \\
\text { em transaçóes de títulos, } \\
\text { valores mobiliários e mercadorias }\end{array}$ & $\begin{array}{c}\text { Previdência } \\
\text { complementar aberta }\end{array}$ & & \\
\hline $\begin{array}{l}\text { Administração de } \\
\text { cartôes de crédito }\end{array}$ & & & \\
\hline $\begin{array}{l}\text { Atividades de administração de } \\
\text { fundos por contrato ou comissão }\end{array}$ & & & \\
\hline
\end{tabular}

Fonte: Elaboração própria, 2010. 
claramente a sua condição de lugar central. ${ }^{11}$ Adicionalmente, das 12 atividades cuja maior participação relativa está no cluster, cinco estão localizadas no primeiro quartil da hierarquia, quatro no segundo e três no terceiro (Tabela 1).

O Centro Financeiro de Segunda $\left(2^{a}\right)$ Ordem, por sua vez, abriga dez atividades, cuja respectiva participação relativa é maior dentro desse cluster. Destas, três estão localizadas no primeiro quartil da hierarquia, cinco no segundo e duas no terceiro.

Finalmente, os dois últimos clusters - Sistema Financeiro Diversificado e Sistema Financeiro Básico - abrigam atividades cuja participação relativa é maior nos respectivos clusters que estão localizados exclusivamente no terceiro quartil - para o caso do cluster Sistema Financeiro Diversificado - e no último quartil - para o caso do cluster Sistema Financeiro Básico.

O que fica evidente da análise anterior é a hierarquização do sistema financeiro brasileiro com poucos centros oferecendo serviços financeiros mais sofisticados e uma gama enorme de municípios atendidos pelos serviços básicos. Dito em outras palavras, os resultados mostram grande fragmentação na hierarquia urbana brasileira, com poucos
11 A única exceção é a atividade "Fundo de investimento”, que não está presente neste cluster. No entanto, vale salientar que essa atividade também é efetuada por outros tipos de instituição, tais como "Bancos comerciais".
Tabela 7_ Distribuição regional dos clusters

\begin{tabular}{l|c|c|c|c|c|c}
\multicolumn{1}{c|}{ Cluster* } & Norte & Nordeste & Sudeste & Sul & Centro-Oeste & Total \\
\hline SFB & 213 & 987 & 1281 & 994 & 323 & 3800 \\
\hline SFD & 2 & 9 & 15 & 2 & 3 & 31 \\
\hline CF $2^{\circ}$ & 0 & 0 & 2 & 2 & 1 & 5 \\
\hline CF $1^{\circ}$ & 0 & 0 & 1 & 0 & 0 & 1 \\
\hline Total & 217 & 996 & 1299 & 998 & 327 & 3837 \\
\hline
\end{tabular}

Fonte: Elaboração Própria, 2010.

${ }^{*} \mathrm{SFB}=$ Sistema Financeiro Básico.

$\mathrm{SFD}=$ Sistema Financiero Diversificado.

$\mathrm{CF} 2^{\circ}=$ Centro Financeiro de Segunda Ordem .

$\mathrm{CF} 1^{\circ}=$ Centro Financeiro de Primeira Ordem . 
polos de ordem superior que prestam serviços mais complexos, como os apontados no caso do setor financeiro.

A Tabela 7 mostra a distribuição dos municípios de cada cluster entre as grandes regióes.

Como pode ser verificado, existe forte concentração regional dos clusters analisados. Nas regióes menos desenvolvidas - Norte e Nordeste -, os clusters de maior nível hierárquico não possuem nenhuma cidade no seu interior. Ou seja, os Centros Financeiros de Primeira e Segunda. Ordens localizam-se em regióes mais desenvolvidas. Esses clusters são caracterizados por possuírem maior financial deepening, revelado através da maior diversidade de tipos de instituição financeira no seu interior e da escala das atividades. Tais resultados corroboram as conclusóes segundo as quais o sistema financeiro brasileiro contribui para o quadro atual de disparidades regionais no Brasil.

\section{6_Hierarquia financeira e estratégia bancária no território}

Como visto anteriormente, existe relação entre o grau de centralidade de uma determinada região e o grau de preferência pela liquidez das agências bancárias ali instaladas: quanto maior a cen- tralidade, menor seria a preferência pela liquidez. A decorrência dessa argumentação seria a existência de estratégias diferenciadas espacialmente de gerenciamento bancário de acordo com a preferência da liquidez das agências bancárias.

Para testar essa hipótese, foi utilizada uma série de indicadores que captam diferentes aspectos da gestão bancária, ${ }^{12}$ a saber:

\section{Indicadores de Tamanho do Sistema Financeiro}

_ Ativo Total / PIB: este indicador mede o tamanho relativo do sistema bancário em relação à economia local;

_ Ativo Total / População: possui o mesmo significado do anterior; porém, utiliza a população como medida do tamanho de uma região.

Existe uma extensa literatura que estuda a relação entre sistema financeiro e crescimento econômico, o chamado "nexo finanças-crescimento" ( $f$ nance-growth nexus). Entre os vários indicadores usados para mensurar esse nexo, os dois acima citados são comumente utilizados e considerados como proxies do grau de desenvolvimento do sistema financeiro, principalmente na literatura novo keynesiana (Levine, 2004, entre outros).
12 Para uma descrição detalhada desses indicadores, ver Crocco (2010), Crocco et al. (2010a e 2010b). 
Indicadores de Gerenciamento do Ativo

_ Preferência pela Liquidez das

Agências Bancárias (PLB): mede a disposição da agência

bancária em se tornar

mais ilíquida, através do

fornecimento do crédito, sendo

calculada por meio da razão

entre o item do passivo mais

líquido (depósitos à vista) e

o mais ilíquido item do ativo

(crédito concedido). Quanto

maior esse indicador, maior

a preferência pela liquidez da agência bancária (ou menor a disposição em emprestar e se tornar mais ilíquido) (Crocco $e t$ al., 2005-6); $;^{13}$

13 O fato de a abordagem aqui adotada em relação à oferta de moeda afirmar que a concessão de crédito não é limitada pelo volume das reservas (visão estruturalista da oferta de moeda) não significa dizer que não existem custos para o banco se tornar ilíquido. Assume-se que existe um custo, quer seja em recorrer ao Banco Central para a obtenção de empréstimos de liquidez (no caso de um banco como um todo), quer seja em recorrer

à matriz para um socorro de tesouraria (no caso de uma agência bancária). $\mathrm{O}$ indicador de preferência pela liquidez proposto capta justamente em que medida a agência bancária está disposta a incorrer nesse custo.

14 Este indicador é uma versão modificada do quociente locacional, amplamente utilizado na literatura de economia regional.
_ Lucro sobre Ativo: é a razão entre o total de lucro auferido pela agência bancária em relação ao total do ativo dessa agência. Indica a capacidade do sistema bancário em transformar seus ativos em lucro;

_ Quociente Regional de Crédito: é a razão entre a participação relativa da regiáo no total de volume de crédito concedido no país e a participação relativa da mesma regiáo no total do PIB do país. ${ }^{14}$ Se essa razão for maior do que 1 , a concessão de crédito na regiāo é maior do que se poderia esperar em função do seu PIB;

- Crédito Total / Ativo Total: mede a proporção do crédito concedido em relação ao total do ativo. É de se esperar que, quanto maior a preferência pela liquidez das agências, menor o valor deste indicador;

_ Títulos e Valores Imobiliários / Ativo Total: este indicador capta o total de operaçóes das agências bancárias com títulos e valores imobiliários sobre o total do ativo. Como esse tipo de ativo é de elevada liquidez, quando comparado com a concessão de crédito, é esperado 
que maior preferência pela liquidez dos bancos em uma região implique maior peso de títulos e valores mobiliários em relação ao total de ativos;

_ Provisão para Créditos em Liquidação / Crédito Total: é a medida da qualidade do crédito em uma região específica. É a razão entre o total de dinheiro que as agências devem reservar em função da expectativa de inadimplência e o total do crédito concedido. Quanto menor este indicador, melhor a qualidade do crédito concedido.

\section{Indicadores de Gerenciamento do Passivo}

_ Depósitos à Vista / Total do Passivo: os depósitos à vista representam a obrigação mais líquida que o banco possui em seu passivo. Assim, quanto maior for este indicador, maior a necessidade de o banco possuir reservas. Embora as agências bancárias sempre possam recorrer às suas respectivas sedes para o suprimento de reservas quando necessário, assumese neste trabalho que essa não é uma opção desejável, uma vez que ela pode indicar mau gerenciamento;

_ Depósitos a Prazo / Passivo Total: os depósitos a prazo representam um tipo de depósito que supostamente não será retirado do sistema bancário no curto prazo, uma vez que normalmente existe alguma renumeração associada com o tempo com que o depósito fica no banco. Assim, ele representa um tipo de passivo com baixo grau de liquidez, significando que os bancos não precisam manter elevada proporção de reservas de precaução para fazer frente a possíveis retiradas pelos depositantes. No caso brasileiro, essa conta representa todas as formas de investimentos financeiros feito pelo público, tais como açôes, títulos governamentais, fundos de investimentos, etc.;

_ Poupança / Passivo Total: comparativamente com os depósitos à vista e a prazo, a poupança pode ser considerada o mais ilíquido dos itens do passivo, já que ela representa a parcela de recursos da 
população destinada a fazer frente ou a situações inesperadas ou a aumento futuro do consumo. Especialmente no caso brasileiro, a poupança é basicamente a única forma de investimento financeiro para a população mais pobre, visto que não requer valor mínimo de recursos necessários para investir. Entretanto, comparativamente com outras formas de investimento financeiro captados na conta Depósitos a Prazo, a remuneração da poupança é muito baixa.

Esses três indicadores constituem proxies do gerenciamento do passivo por parte da agência bancária. Considera-se que, quanto menor o indicador Depósitos à Vista / Passivo Total e quanto maior os outros dois indicadores, mais bem-sucedido está sendo o gerenciamento do passivo da agência, uma vez que tornam menos líquido o passivo. Tal situação será aqui denominada de "forte gerenciamento do passivo". Situaçóes contrárias serão denominadas "fraco gerenciamento do passivo".

$\mathrm{Na}$ Tabela 8, os valores desses indicadores são mostrados.
Como pode ser observado, fica evidente a existência de estratégias diferenciadas de acordo com o grau de centralidade. Iniciando pelo peso do sistema bancário na região, nota-se um padrão já esperado, ou seja, o sistema bancário apresenta maior escala nos municípios de maior centralidade.

O gerenciamento do ativo também mostra evidente diferenciação das estratégias bancárias. Primeiramente, observa-se que os municípios dos clusters de menor nível hierárquico apresentam maior preferência pela liquidez, menores quocientes regionais de crédito e maiores indicadores de lucratividade. Ou seja, apesar de não existir especialização no fornecimento de serviços para os municípios localizados nos clusters de níveis hierárquicos mais baixos, o sistema bancário aí localizado consegue auferir lucratividade maior. Ademais, fornece crédito abaixo do que poderia ser esperado tendo em vista o peso desses municípios nos seus respectivos PIBs.

Vale notar também o peso que tanto a concessão de crédito e a aplicação em títulos e valores mobiliários (TVM) possuem em cada cluster. Como era de se esperar, os Centros Financeiros de Primeira e Segunda Ordens apresentam, relativamente, maiores valores para o peso das aplicaçóes de TVM sobre 
o total do ativo do que os Sistemas Financeiros Básicos e Diversificados. Isso seria derivado da própria diversidade de tipos de instituição financeira existentes nos Centros Financeiros. Destaca-se ain- da o fato de, no Centro Financeiro de Primeira Ordem, o peso das aplicaçôes de TVM no total do ativo das agências ser maior do que o peso do total de crédito concedido.

Tabela 8_ Indicadores de gestão bancária por cluster

\begin{tabular}{|c|c|c|c|c|}
\hline Indicador & $\begin{array}{c}\text { Sistema } \\
\text { Financeiro Básico }\end{array}$ & $\begin{array}{l}\text { Sistema Financeiro } \\
\text { Diversificado }\end{array}$ & $\begin{array}{l}\text { Centro Financeiro } \\
\text { de } 2^{\mathrm{a}} \text { Ordem }\end{array}$ & $\begin{array}{c}\text { Centro Financeiro } \\
\text { de } 1^{\text {a }} \text { Ordem }\end{array}$ \\
\hline \multicolumn{5}{|c|}{ Tamanho do Sistema Bancário } \\
\hline Ativo/População & $2.221,04$ & $28.153,11$ & $75.256,52$ & $213.424,58$ \\
\hline Ativo/PIB_06 & 0,20 & 1,11 & 3,22 & 4,94 \\
\hline \multicolumn{5}{|l|}{ Gerenciamento do Ativo } \\
\hline Lucro/Ativo* & 1,18 & 0,54 & 0,30 & 0,03 \\
\hline TVM/Ativo & 0,00 & 0,04 & 0,06 & 0,17 \\
\hline PLB & 0,37 & 0,25 & 0,71 & 0,09 \\
\hline QRC_06 & 0,26 & 0,59 & 1,10 & 2,31 \\
\hline Crédito Total/Ativo & 0,69 & 0,44 & 0,32 & 0,15 \\
\hline $\begin{array}{l}\text { Crédito em liquidação/ } \\
\text { Crédito Total* }\end{array}$ & $-1,71$ & $-3,13$ & $-3,81$ & $-4,08$ \\
\hline
\end{tabular}

\section{Gerenciamento do Passivo}

\begin{tabular}{l|c|c|c|c}
\hline Depósitos a prazo/Passivo & 0,13 & 0,18 & 0,15 & 0,07 \\
\hline Depósitos à vista privado/Passivo & 0,15 & 0,09 & 0,03 \\
\hline Poupanças/Passivo & 0,44 & 0,18 & 0,04 \\
\hline
\end{tabular}

Fonte: Elaboraçáo própria, 2010.

*Para facilitar a visualizaçáo, os valores foram multiplicados por 100. 
Por outro lado, nos municípios que possuem Sistemas Financeiros de menor nível hierárquico, o peso da concessão de crédito sobre o ativo é maior do que o observado nos Centros Financeiros. Isso seria explicado pelo fato de os municípios desses clusters servirem como captadores de reservas a ser transferidas para os Centros Financeiros para que estes operem no mercado de TVM. Assim, a forma essencial das agências bancárias de sistemas financeiros menos centrais de buscar lucratividade resumir-se-ia à concessão de crédito - embora em menor proporçáo do que seria esperado dada a estrutura produtiva local (vide o valor do QRC) - e a cobrança de taxas de serviços bancários.

Por fim, o indicador de qualidade do crédito mostra que ele vai piorando quando se passa do cluster menos hierárquico para clusters de níveis superiores. Esse resultado pode ser interpretado de duas formas. Em primeiro lugar, como, proporcionalmente, o volume de empréstimos concedidos é maior nos Centros Financeiros, deve ser esperado que maior quantidade de empréstimos com problemas de pagamento também ocorra nos Centros Financeiros. Em segundo lugar, dado que a preferência pela liquidez é maior nos clusters de menor nível hierárquico, tais resultados podem refle- tir maior aversão ao risco desses clusters. Essa aversão faz com que não somente o volume de crédito concedido seja proporcionalmente menor (QRC), como também a qualidade desse seja melhor. Em outras palavras, concede-se pouco crédito e somente para clientes com evidente capacidade de pagamento.

\section{7_Conclusão}

O presente trabalho procurou tratar da relaçáo entre centralidade urbana e hierarquia do sistema financeiro. Para tanto, desenvolveu inicialmente a argumentação teórica que sustenta a referida relação. Mostrou-se que a centralidade de uma regiáo afeta o processo de concessão de finance e de funding pelo sistema financeiro desta, com claras implicaçôes sobre o processo de desenvolvimento econômico que ali se desenvolve. A importância dessa argumentaçâo está no fato de mostrar que o funcionamento do sistema financeiro não é indiferente ao processo de construção tanto das cidades e de seu núcleo urbano, como também do processo de hierarquização urbana daí resultante. Como visto, a possibilidade de um sistema financeiro desempenhar um papel ativo no desenvolvimento de uma região 
e/ou cidade está diretamente relacionada com o grau de centralidade dessa regiáo.

Esse entendimento teórico foi confirmado pela análise empírica realizada para o caso brasileiro. A partir da categorização dos diversos tipos de instituição financeira, foi possível classificar as cidades brasileiras em clusters de acordo com o grau de sofisticação e diversidades dos serviços financeiros oferecidos. Como visto, a hierarquia e a centralidade do sistema financeiro brasileiro são enormes (fato esse teoricamente compatível com a construção de hierarquias urbanas em espaços periféricos). Como mostrado, as cidades brasileiras podem ser agrupadas em cinco clusters quando analisadas em função de seu sistema financeiro: Centro Financeiro de Primeira Ordem, com uma cidade apenas - São Paulo; Centros Financeiros de Segunda Ordem, com cinco cidades - Rio de Janeiro, Brasília, Curitiba, Belo Horizonte e Porto Alegre; Sistema Financeiro Diversificado, com 31 cidades; Sistema Financeiro Básico, com 3.800 cidades e os demais 1.721 municípios que só possuem caixas eletrônicos.

Além dessa concentração, que mostra como é diferenciada no espaço a capacidade do sistema financeiro em participar ativamente do processo de desenvolvimento em distintas regióes, fi- cou evidenciada como a gestão bancária também é diferenciada, não restando dúvidas de que o sistema financeiro desempenha papel-chave na explicação das disparidades regionais no Brasil. 


\section{Referências bibliográficas}

\author{
ABLAS, L. A Teoria do Lugar \\ Central: Bases teóricas e \\ evidêncisa empíricas. São \\ Paulo: USP, 1982.
}

ALESSANDRINI, P. et al. Bank Size or Distance: what hampers innovation adoption by SMEs? Working Papers, 304, Universitá Politecnica delle Marche, Dipartimento di Economia, 2007

AMADO, A. Disparate regional development in Brazil: A monetary produtction approach. Brookfield: Ashgate Publishing Company, 1997.

BECKMANN, M. Location theory. Random House:

New York, 1968.

BENNETT, R.; GRAHAM, D.

Explaining size differentiation of business service centres. Urban Studies, v. 35, n. 9 , p. 1457-1480, 1998.

BERRY, B.; PRED, A. Central Places Studies: A bibliography of theory and applications. Philadelphia, Penn: Regional Science Research Institute, 1961.

BERRY, B. "Cities as Systems Within Systems of Cities." Papers of the Regional Science Association, n. 13, p. 147-163, 1964.
CARVAlHO, F. Mr. Keynes and the Post Keynesians. Brookfield: Edward Elgar, 1992.

CHICK, V. The evolution of the banking system and the theory of of saving, investment and interest. In: On Money, Method and Keynes: Selected papers of Victoria Chick. London: Mcmillan, 1992.

CHICK, V.; DOW, S. A Post Keynesian perspective on the relation between banking and regional development. In: ARESTIS, P. (Ed.). Post Keynesian Monetary Economics: New approaches to financial modeling, Aldershot: Edward Elgar, 1988.

\section{CHRISTALLER, W. Central}

places in southerm Germany. New Jersey: Prentice-Hall, 1966 [1933].

\section{CROCCO, M. Moeda e} desenvolvimento regional e urbano: Uma leitura keynesiana e sua aplicação ao caso brasileiro. Tese de Titular, Faculdade de Ciências Econômicas, UFMG, Belo Horizonte, 2010.

CROCCO, M. et al.

Differentiated banking strategies across the territory: An exploratory analysis. Journal of Post Keynesian Economics, v. 33, p. $127-150,2010$ a
CROCCO, M. et al. The spatial structure of the financial development in Brazil. Spatial Economic Analysis, v. 5, p. 181-293, 2010b.

CROCCO, M. et al. The behavior of liquidity preference of banks and public and regional development: The Case of Brazil. Journal of Post Keynesian Economics, v. 28, n. 2, p. 21740, Winter 2005-2006.

\section{DAVIDSON, P. Money} and the real world. Londres, Macmillan, 1972.

DEMSETZ, $\mathrm{H}$. The cost of transacting. The Quarterly Journal of Economics, v. 82, n. 1, p. 33-55, 1968.

DICKEN, P.; LLOYD, P. Location in space: Theoretical perspectives in Economic Geography. 3rd. Ed. New York: Harper Collins, 1990.

DOW, S. Money and the Economic Process. Aldershot, Elgar. 1993.

DOW, S. The stages of banking development and the spatial evolution of financial systems. In: MARTIN, R. (Ed.). Money and the Space Economy. New York, John Wiley and Sons, 1999.
DOW, S.; HILLARD, J. (Eds.). Keynes, knowledge and uncertainty. Aldershot: Edward Elgar, 1995.

ESTALL, R. A modern geography of the United States: Aspects of life and economy. Harmondsworth, Penguin, 1972.

GERTLER, M.; ROSE, A. Finance, public policy and growth. In: CAPRIO G., ATILJAS, I.; HANSON, J. A. (Eds). Financial Reform: Theory and experience. Cambridge University Press, New York, p. 13-45, 1984.

JACOBS, J. The Economies of the City. New York: Vintage Books, 1968.

\section{KEYNES, J. M. Relative} movements of real wages and output. The Economic Journal, v. 49, i. 193, 34-51. 1973 [1939].

KEYNES, J. M. The distinction between a co-operative economy and an entrepreneur economy. In KEYNES, J. M. Collected writings ofJ. M. Keynes. London: Mac Millan/Cambridge University. v. 13, p. 76-87, 1979 [1933]

KEYNES, J. M. The General Theory of Employment, Interest and Money. Londres: Macmillan, 1973 [1937]. 
LEMOS, M. Espaço e capital: Um estudo sobre a dinâmica centro x periferia. 1988. (Doutorado em Economia) - Instituto de Economia, Universidade Estadual de Campinas Unicamp, Campinas, 1988.

LÖSCH, A. The economics of location. Yale United Press: New Haven, 1954.

MARTIN, R. The new economic geography of money. In: MARTIN, R. (Ed.). Money and the Space Economy. New York, USA: John Willey \& Sons, p. 3-27, 1999.

MARTIN, R. Money and the Space Economy. New York, John Wiley and Sons, 1999.

MOORE, C .L.; HILL, J. M. Interregional arbitrage and the supply of loanable funds. Journal of Regional Science, v. 22, p. 499-512, 1982.

PARR, J. The law of market areas and the size distribution of urban centres. Papers in Regional Science, v. 76, n. 1, p. 43-68, 1997.

PARR, J.; BUDD, L. Financial services and the urban system: An exploration. Urban Studies, v. 37, n. 3, p. 593-610, 2000.

ROBERTS, R. B.; FISHKIND,

$\mathrm{H}$. H. The role of monetary forces in regional economic activity: An econometric simulation analysis. Journal of Regional Science, v. 19, n. 1, p. 15-29, 1979.

RODRIGUEZ-FUENTES,

C. Regional Monetary Policy. Londres: Routledge, 2006.
SAMOLYK, K. A. Banking conditions and regional economic performance. Journal of Monetary Economics, v. 34, p. 259-278, 1994.

\section{SANTOS, F.; CROCCO,}

\section{M.; LEMOS, M. Sistemas}

produtivos locais em 'espaços industriais periféricos': Os casos de Nova Serrana e da rede FIAT de fornecedores. Revista de Economia Contemporânea, n. 6 , p. 147-180, 2002

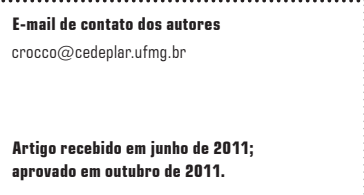




\section{Anexos}

\section{Quadro 1_ Tipos de instituições financeiras}

\begin{tabular}{|c|c|c|}
\hline $\begin{array}{c}\text { Bancos Comerciais }+ \\
\text { Bancos Múltiplos com carteira comercial }\end{array}$ & Arrendamento mercantil & Fundos de investimento \\
\hline Caixas Econômicas & Sociedades de capitalização & $\begin{array}{l}\text { Sociedades de fomento mercantil } \\
\text { - factoring }\end{array}$ \\
\hline Crédito cooperativo & Holdings de instituições financeiras & Securitização de créditos \\
\hline Bancos múltiplos sem carteira comercial & Holdings de instituiçôes não-financeiras & $\begin{array}{c}\text { Administração de consórcios } \\
\text { para aquisição de bens e direitos }\end{array}$ \\
\hline Bancos de investimento & $\begin{array}{c}\text { Outras sociedades de } \\
\text { participação, exceto holding }\end{array}$ & $\begin{array}{l}\text { Outras atividades de serviços financeiros } \\
\text { náo especificadas anteriormente }\end{array}$ \\
\hline Bancos de desenvolvimento & $\begin{array}{l}\text { Atividades auxiliares dos seguros, } \\
\text { da previdência complementar e dos planos } \\
\text { de saúde náo especificados anteriormente }\end{array}$ & Seguros de vida \\
\hline Agências de fomento & $\begin{array}{l}\text { Atividades de administração de } \\
\text { fundos por contrato ou comissáo }\end{array}$ & Seguros náo-vida \\
\hline Crédito imobiliário & Planos de saúde & Seguros saúde \\
\hline $\begin{array}{l}\text { Sociedades de crédito, financiamento } \\
\text { e investimento - financeiras }\end{array}$ & $\begin{array}{l}\text { Administração de bolsas e } \\
\text { mercados de balcáo organizados }\end{array}$ & Resseguros \\
\hline $\begin{array}{l}\text { Sociedades de crédito } \\
\text { ao microempreendedor }\end{array}$ & $\begin{array}{l}\text { Atividades de intermediários } \\
\text { em transaçóes de títulos, } \\
\text { valores mobiliários e mercadorias }\end{array}$ & Previdência complementar fechada \\
\hline $\begin{array}{l}\text { Bancos de câmbio e outras instituiçóes } \\
\text { de intermediação não-monetária }\end{array}$ & Administração de cartôes de crédito & Previdência complementar aberta \\
\hline $\begin{array}{l}\text { Atividades auxiliares dos } \\
\text { serviços financeiros } \\
\text { não especificadas anteriormente }\end{array}$ & Avaliação de riscos e perdas & $\begin{array}{l}\text { Corretores e agentes de seguros, de planos } \\
\text { de previdência complementar e de saúde }\end{array}$ \\
\hline
\end{tabular}


Tabela 1_Tipos de instituições financeiras mais importantes por cluster

\begin{tabular}{|c|c|c|c|c|}
\hline Classificação & Cluster 1 & Cluster 2 & Cluster 3 & Cluster 4 \\
\hline 1 & $\begin{array}{l}\text { Bancos comerciais + } \\
\text { Bancos Múltiplos } \\
\text { com carteira comercial }\end{array}$ & $\begin{array}{c}\text { Bancos comerciais + } \\
\text { Bancos Múltiplos } \\
\text { com carteira comercial }\end{array}$ & $\begin{array}{c}\text { Bancos comerciais + } \\
\text { Bancos Múltiplos } \\
\text { com carteira comercial }\end{array}$ & $\begin{array}{c}\text { Bancos comerciais }+ \\
\text { Bancos Múltiplos } \\
\text { com carteira comercial }\end{array}$ \\
\hline 2 & Caixas econômicas & Caixas econômicas & Caixas econômicas & Seguros não-vida \\
\hline 3 & Crédito cooperativo & Planos de saúde & Seguros não-vida & $\begin{array}{l}\text { Atividades de intermediários } \\
\text { em transaçóes de títulos, } \\
\text { valores mobiliários e } \\
\text { mercadorias }\end{array}$ \\
\hline 4 & Planos de saúde & Seguros não-vida & Planos de saúde & Caixas econômicas \\
\hline 5 & $\begin{array}{l}\text { Corretores e agentes } \\
\text { de seguros, de planos } \\
\text { de previdência } \\
\text { complementar e de saúde }\end{array}$ & $\begin{array}{c}\text { Corretores e agentes } \\
\text { de seguros, de planos } \\
\text { de previdência } \\
\text { complementar e de saúde }\end{array}$ & $\begin{array}{c}\text { Previdência } \\
\text { complementar fechada }\end{array}$ & Planos de saúde \\
\hline 6 & $\begin{array}{l}\text { Holdings de insituiçóes } \\
\text { não-financeiras }\end{array}$ & $\begin{array}{c}\text { Administração de } \\
\text { consórcio para aquisição } \\
\text { de bens e direitos }\end{array}$ & $\begin{array}{l}\text { Holdings de instituiçóes } \\
\text { não-financeiras }\end{array}$ & $\begin{array}{l}\text { Holdings de instituições } \\
\text { não-financeiras }\end{array}$ \\
\hline 7 & $\begin{array}{c}\text { Administração de } \\
\text { consórcio para aquisição } \\
\text { de bens e direitos }\end{array}$ & Bancos de desenvolvimento & Bancos de desenvolvimento & $\begin{array}{l}\text { Corretores e agentes } \\
\text { de seguros, de planos } \\
\text { de previdência } \\
\text { complementar e de saúde }\end{array}$ \\
\hline 8 & Seguros não-vida & $\begin{array}{l}\text { Holdings de instituiçóes } \\
\text { não-financeiras }\end{array}$ & $\begin{array}{c}\text { Corretores e agentes } \\
\text { de seguros, de planos } \\
\text { de previdência } \\
\text { complementar e de saúde }\end{array}$ & $\begin{array}{c}\text { Bancos múltiplos, } \\
\text { sem carteira comercial }\end{array}$ \\
\hline 9 & $\begin{array}{l}\text { Administração de } \\
\text { cartóes de crédito }\end{array}$ & $\begin{array}{l}\text { Sociedades de crédito, } \\
\text { financiamento e } \\
\text { investimento - financeiras }\end{array}$ & $\begin{array}{l}\text { Atividades de intermediários } \\
\text { em transaçóes de títulos, } \\
\text { valores mobiliários e } \\
\text { mercadorias }\end{array}$ & Seguros-saúde \\
\hline
\end{tabular}


(conclusão)

\begin{tabular}{|c|c|c|c|c|}
\hline Classificação & Cluster 1 & Cluster 2 & Cluster 3 & Cluster 4 \\
\hline 10 & $\begin{array}{c}\text { Atividades auxiliares } \\
\text { de seguros, da previdência } \\
\text { complementar e dos planos } \\
\text { de saúde não especificadas } \\
\text { anteriormente }\end{array}$ & $\begin{array}{l}\text { Administração de } \\
\text { cartões de crédito }\end{array}$ & $\begin{array}{c}\text { Previdência } \\
\text { complementar aberta }\end{array}$ & Seguros de vida \\
\hline 11 & $\begin{array}{l}\text { Sociedade de fomento } \\
\text { mercantil - factoring }\end{array}$ & Crédito cooperativo & Seguros de vida & $\begin{array}{l}\text { Administração de } \\
\text { cartões de crédito }\end{array}$ \\
\hline 12 & $\begin{array}{l}\text { Sociedades de crédito, } \\
\text { financiamento e } \\
\text { investimento - financeiras }\end{array}$ & $\begin{array}{l}\text { Sociedadede fomento } \\
\text { mercantil - factoring }\end{array}$ & Seguros-saúde & $\begin{array}{c}\text { Sociedades de crédito, } \\
\text { financiamento e } \\
\text { investimento - financeiras }\end{array}$ \\
\hline 13 & Seguros de vida & $\begin{array}{c}\text { Previdência } \\
\text { complementar fechada }\end{array}$ & $\begin{array}{l}\text { Atividades auxiliares dos } \\
\text { seguros, da previdência } \\
\text { complementar e dos planos } \\
\text { de saúde náo especificadas } \\
\text { anteriormente }\end{array}$ & $\begin{array}{l}\text { Atividades auxiliares dos } \\
\text { seguros, da previdência } \\
\text { complementar e dos planos } \\
\text { de saúde não especificadas } \\
\text { anteriormente }\end{array}$ \\
\hline 14 & Avaliação de riscos e perdas & $\begin{array}{c}\text { Previdência } \\
\text { complementar aberta }\end{array}$ & Crédito imobiliário & $\begin{array}{l}\text { Administração de } \\
\text { bolsas e mercados } \\
\text { de balcão organizado }\end{array}$ \\
\hline 15 & $\begin{array}{c}\text { Atividades de intermediários } \\
\text { em transaçóes de títulos, } \\
\text { valores mobiliários e } \\
\text { mercadorias }\end{array}$ & Seguros de vida & Crédito cooperativo & Bancos de investimento \\
\hline
\end{tabular}

